\title{
Neurofibromatosis Type 1 With Cherubism-like Phenotype, Multiple Osteolytic Bone Lesions of Lower Extremities, and Alagille-syndrome: Case Report With Literature Survey
}

\author{
REINHARD E. FRIEDRICH ${ }^{1}$, JOZEF ZUSTIN ${ }^{2,3}$, ANDREAS M. LUEBKE ${ }^{4}$, THORSTEN ROSENBAUM ${ }^{5}$, \\ MARTIN GOSAU ${ }^{1}$, CHRISTIAN HAGEL $^{6}$, FELIX K. KOHLRUSCH ${ }^{1}$, ILSE WIELAND ${ }^{7}$ and MARTIN ZENKER ${ }^{7}$ \\ ${ }^{1}$ Oral and Craniomaxillofacial Surgery, Eppendorf University Hospital, \\ University of Hamburg, Hamburg, Germany; \\ ${ }^{2}$ Institute of Osteology and Biomechanics, Eppendorf University Hospital, \\ University of Hamburg, Hamburg, Germany; \\ ${ }^{3}$ Institute of Pathology, Gemeinschaftspraxis Pathologie-Regensburg, Regensburg, Germany; \\ ${ }^{4}$ Institute of Pathology, Eppendorf University Hospital, University of Hamburg, Hamburg, Germany; \\ ${ }^{5}$ Department of Pediatrics, Sana-Kliniken Duisburg, Duisburg, Germany; \\ ${ }^{6}$ Institute of Neuropathology, Eppendorf University Hospital, University of Hamburg, Hamburg, Germany; \\ ${ }^{7}$ Institute of Human Genetics, Otto-von-Guericke University Magdeburg, Magdeburg, Germany
}

\begin{abstract}
Background/Aim: Neurofibromatosis type 1 (NF) is an autosomal dominant hereditary disease. The cardinal clinical findings include characteristic skeletal alterations. Difficulties in diagnosis and therapy can arise if an individual has further illnesses. Case Report: This is a case report of a 16-year-old patient affected by NF1. She also suffered from Alagille syndrome and the consequences of fetal alcohol exposure. The patient's facial phenotype showed findings that could be assigned to one or more of the known diseases. The patient was referred for treating a cherubismlike recurrent central giant cell granuloma (CGCG) of the jaw. The patient developed bilateral, multilocular nonossifying fibromas (NOF) of the long bones of the lower extremity. Treatment of the skeletal lesions consisted of local curettage. While NOF regressed after surgery, the CGCG of the jaw remained largely unchanged. Extensive genetic tests confirmed a previously unknown germline mutation in the JAG1 gene, the germline mutation of the NF1 gene, and the
\end{abstract}

This article is freely accessible online.

Correspondence to: Prof. Reinhard E. Friedrich, MD, DMD, Ph.D, FEBOMFS, Oral and Craniomaxillofacial Surgery, Eppendorf University Hospital, University of Hamburg, Martinist. 52, D-20246 Hamburg, Germany. Tel: +49 40741053259, e-mail: rfriedrich@uke.de

Key Words: Neurofibromatosis type 1, cherubism, central giant cell granuloma, central giant cell lesion, non-ossifying fibroma, JaffeCampanacci syndrome, Alagille syndrome, root resorption. somatic mutation in the NFI gene in the diffuse plexiform neurofibroma, but not in the CGCG. Conclusion: Assigning facial findings to a defined syndrome is ambiguous in many cases and especially difficult in patients who have multiple diseases that can affect the facial phenotype. Surgical therapy should be adapted to the individual findings.

Neurofibromatosis type 1 (NF1) is an autosomal dominant inherited disorder (1). The disease has a high penetrance (about 100\%). However, the phenotype is extremely variable (2). The NF1 gene is located on chromosome $17 \mathrm{q} 11.2(3,4)$. NF1 is a tumor suppressor gene syndrome (5) and the most common monogenetic disease predisposing to cancer (1). NF1 is primarily characterized by multiple skin tumors. The tumors are of neurogenic origin termed neurofibroma. Somatic mutations of NF1 gene in neurofibroma arise in Schwann cells or precursors of Schwann cells. Since Schwann cells originate from the neural crest, NF1 is rated among the diseases that are characterized by mutations in neural crest cells (6). The frequent and numerous neoplasms of NF1 patients arise primarily from the connective soft tissues. Genetic studies show that many of the different neoplasms arising in NF1 patients meet the criteria of somatic allelic loss of NF1 gene according to Knudson's two-hit hypothesis of tumor development (7). However, the unusual variety of symptoms and findings in NF1 patients go far beyond the spectrum of neoplastic lesions (1). Most cases are diagnosed by clinical examination (Table I). Diagnosis and treatment of NF1 patients can be made more difficult if other diseases develop in the same individual and 
Table I. Clinical diagnostic criteria of Neurofibromatosis type 1.

\begin{tabular}{|c|c|c|}
\hline Finding & Typical age at which the finding is to be proven & Examination tool \\
\hline $\begin{array}{l}\geq 6 \text { Cafe au lait spots of integument } \\
\text { (maximum diameter }>5 \mathrm{~mm} \\
\text { prior to puberty, }>15 \mathrm{~mm} \text { post puberty) }\end{array}$ & Congenital or in early childhood & Inspection \\
\hline Axillary and inguinal freckling & Congenital or in early childhood & Inspection \\
\hline 1. Two or more neurofibroma or & 1. Post puberty & Inspection, magnetic resonance \\
\hline 2. One plexiform neurofibroma & 2. Usually congenital & imaging, ultrasound \\
\hline Two or more Lisch nodules (iris hamartoma) & More than $95 \%$ of cases after the age of 15 years & Inspection, slit lamp \\
\hline $\begin{array}{l}\text { Certain bone lesions } \\
\text { (sphenoid bone dysplasia; bowing } \\
\text { and pseudarthrosis of long bones) }\end{array}$ & Congenital, aggravation over time possible & Inspection, $\mathrm{X}$-rays \\
\hline First grade relative with diagnosis of NF1 & - & Medical history \\
\hline
\end{tabular}

the diseases' phenotypes have some similarities. This report summarizes diagnosis and therapy in an NF1 patient who suffered from several diseases. The patient has developed several symptoms and their assignment to individual disease entities was difficult; it was supported by molecular genetic analyzes. The various diseases had a significant impact on the phenotype and choice of treatment.

\section{Case Report}

The female patient, who was 16 years of age at the initial examination, was referred to the Oral and Craniomaxillofacial Surgery Clinic, Eppendorf University Hospital, for treatment of extensive jaw tumors, known to be central giant cell granuloma (CGCG) of jaws. On admission, the small-sized patient had a prominent, broad face with a clear asymmetry in favor of the right side regarding the median-sagittal plane (Figure 1).

Medical history. The medical reports describe a newborn small for gestational age who had to compensate for physical underdevelopment caused by alcohol embryopathy. Furthermore, the medical reports show that the newborn developed hepatobiliary symptoms soon after birth suspicious of Alagille syndrome (underdeveloped hepatobiliary duct system and pulmonary artery stenosis). The medical reports detail that the suspected diagnosis of Alagille syndrome (ALGS) was already documented for the biological father (findings: pulmonary artery stenosis and discolored feces). Both the father's parents also had pulmonary artery stenosis. The toddler was diagnosed with a mild pulmonary artery stenosis that did not require treatment. When examining the patient at the age of 13 years, no pulmonary artery stenosis was found, and the patient was classified as healthy regarding pulmonary artery function.

NF1 was known in the birth mother who suffered from internal hydrocephalus. The patient developed numerous caféau-lait (CAL) spots and axillary and inguinal freckling within the first year, so the diagnosis of NF1 was made. Neither in the only other child of the parents (sister) nor in other half-siblings were one of the two syndromes diagnosed. A few weeks after birth, the patient was admitted to a nursing home and since then has grown up there. Vitamin deficiencies were diagnosed in the postnatal period, including a conspicuous vitamin D deficiency. Metabolic deficiencies related to vitamin uptake and impaired function of hepatobiliary system were treated with adapted dietary supplements. In the further development of the child, a moderate learning disability was diagnosed, and the child has attended a special school. Numerous examinations were carried out during treatment, which revealed several findings (Figures 2, 3, 4, 5, 6, 7 and 8).

Eyes and orbit. No Lisch nodules were found during the initial examination. Lisch nodules were diagnosed at the age of 19 years. Reports of magnetic resonance imaging (MRI) and computed tomography (CT) detail exclusion of orbital plexiform neurofibroma and limitation of osseous lesions to the maxillary process of the orbital floor (Figures 2 and 3). Repeated ophthalmological checks have revealed normal findings, which only required a correction of the refractive power of the eye lenses by glasses.

Face, head and neck. The patient has frontal bossing (head circumference $54 \mathrm{~cm}$ ) and a saddle nose with the tip pointing upwards. The eyes are deep in the orbit and the hyperpigmented skin looks a little darker around the lids than in the periorbital region (Figure 1). There is slight facial asymmetry in favor of the right side due to lateral expansion of the mandible and a more prominent right zygomaticomaxillary complex. The patient uses glasses that cannot be brought into the correct position due to tumorous bone expansion of the right zygomatico-maxillary complex involving the orbital rim (Figure 1). The patient has a prominent chin. No enlarged cervical lymph nodes were noted on palpation of the neck and using B-scan ultrasound imaging. 

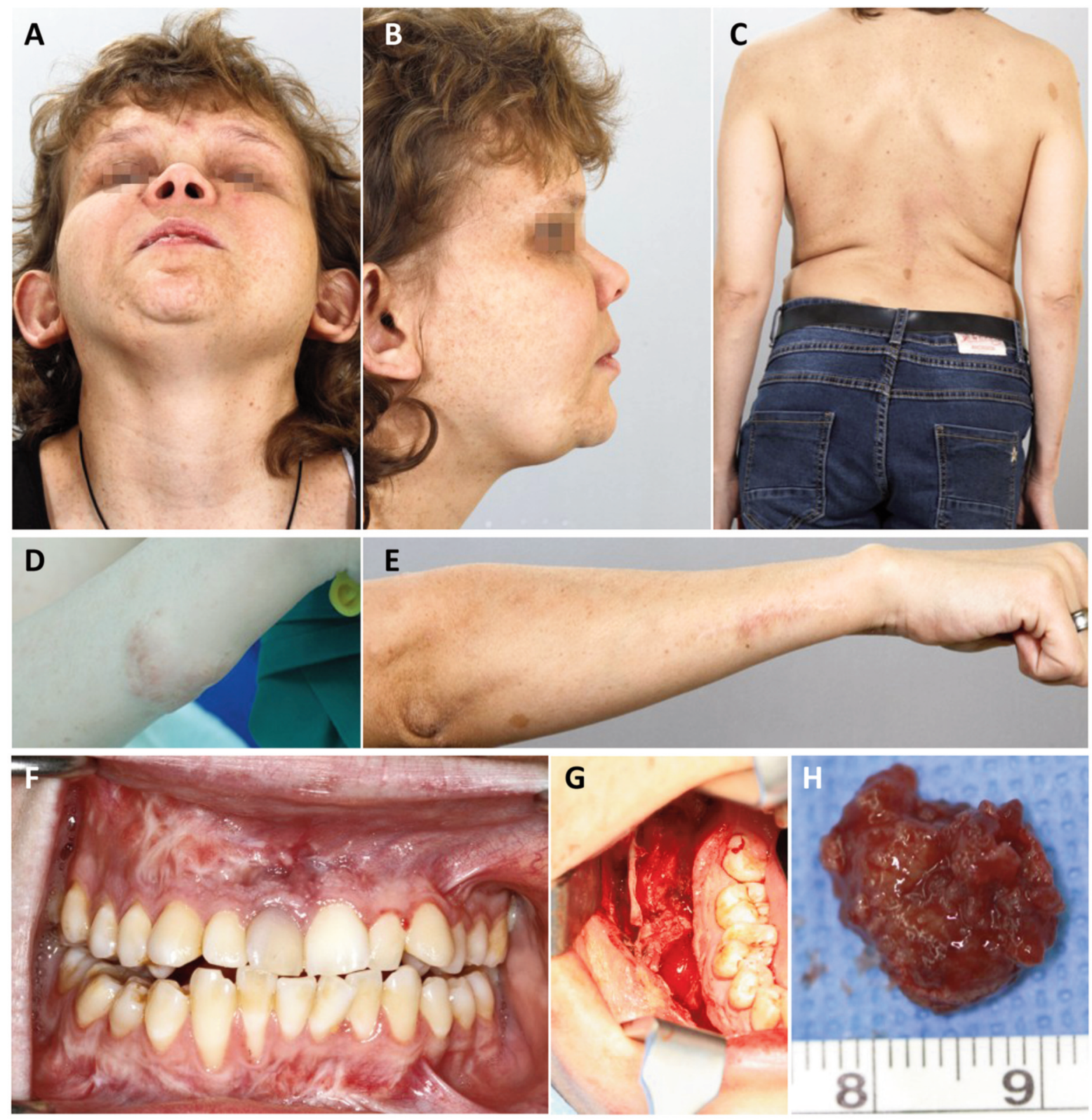

Figure 1. Clinical findings in a patient with NF1 and cherubism-like phenotype. (A) View en face from below. The bilateral cheek swelling is noticeable. The photograph reveals tumorous protrusions on the right margin of the lower jaw next to the chin, broad glabella, hyperpigmentation of the eye lids and multiple small lentigines with perioral accumulation. (B) View from the side shows prominent glabella, flat nose and lips, flattened philtrum, and mandibular tumorous protrusion. (C) Dorsal view of the patient shows further pigmentation disorders and the crooked position of the hips. $(D)$ A diffuse plexiform neurofibroma of the right forearm is depicted prior $(D)$ and after $(E)$ surgical intervention. $(F)$ The oral mucosa has scarred after several surgical interventions and is otherwise normal. The dark discolored upper right central incisor is non-vital after dental trauma. $(G)$ Oral aspect after detachment of the vestibular mucosa and excavation of the soft tissue tumor. Note the significantly thinned cortical bones. Figure (H) shows a representative specimen of the bone tumors.

Jaws. At the age of 16 , the patient was operated on the jaw for the first time in another hospital. Soft tissue tumors had developed within the bone and caused both cortical defects and deformation of the bone. Several tumors of the lower jaw were removed. Right mandibular nerve neurolysis had been performed during the procedure. Since the intervention, there is permanent hypoesthesia of the lower lip on the right side. Tissue examination of the lesions revealed CGCG (vide 

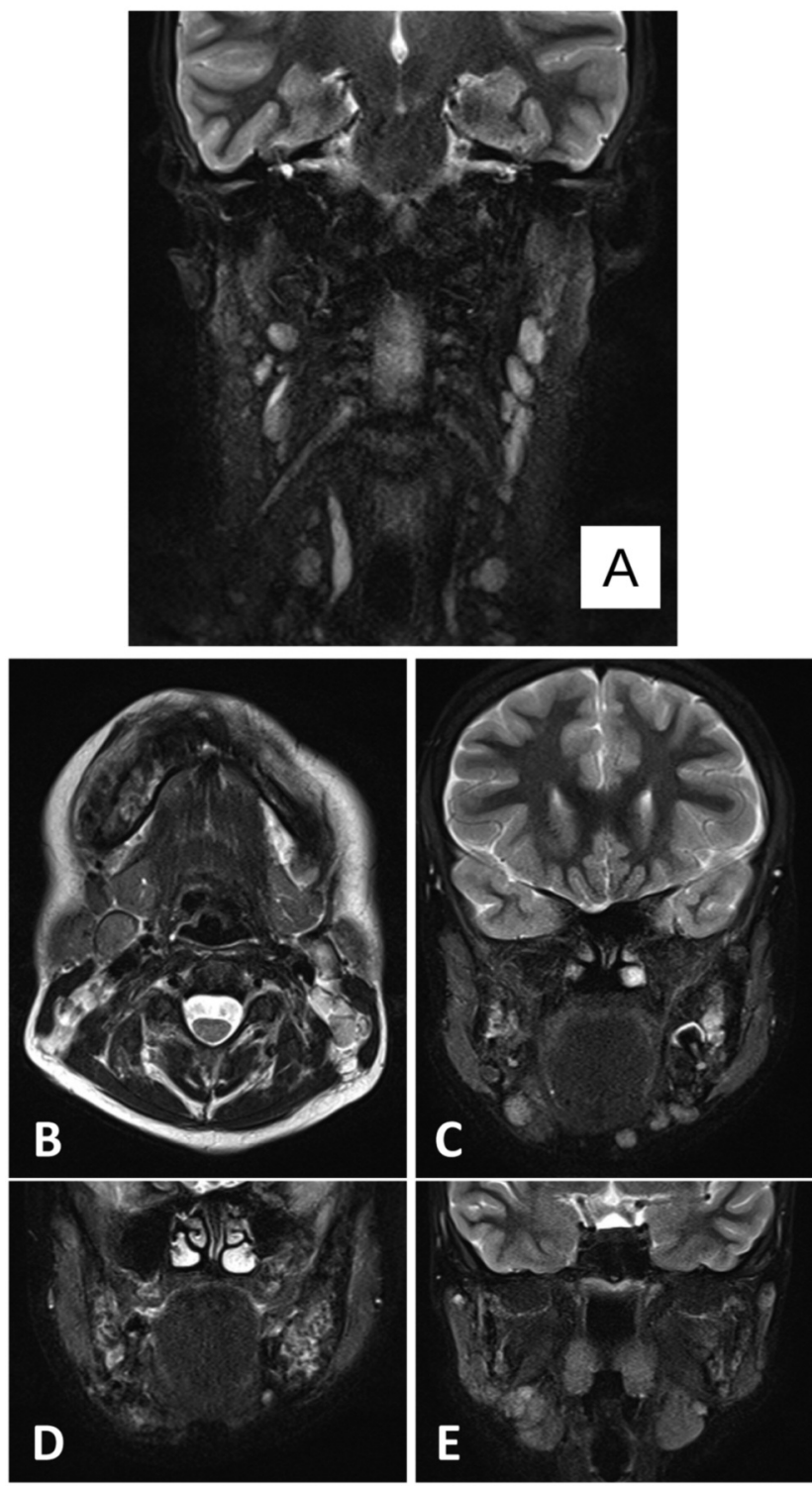

Figure 2. Magnetic resonance images of patient with NF1 and cherubism-like phenotype. (A) Coronal view shows bilateral nodular neurofibroma of the neck arranged in string-like pattern. (B) Axial view shows bilateral inhomogeneous enhancement of mandibular cancellous bone. Expansion of the lesion is noticeable on the right side. Signal hyperintensities are obvious in adjacent buccal soft tissues. (C) Coronal view shows basal nodular lesions. (D) Coronal view shows expansion of lesions in both mandibular angles and rami. (E) Adjacent skull base is not affected by lesions.

infra). Magnetic resonance imaging (MRI) performed before the surgical procedure revealed dysplastic changes in the facial skull. Bilateral and multilocular sharply defined lesions within the bone are hyperintense to the adjacent soft tissues. However, the osseous signaling was in continuity to adjacent soft tissues of the oral cavity and cheek, possibly
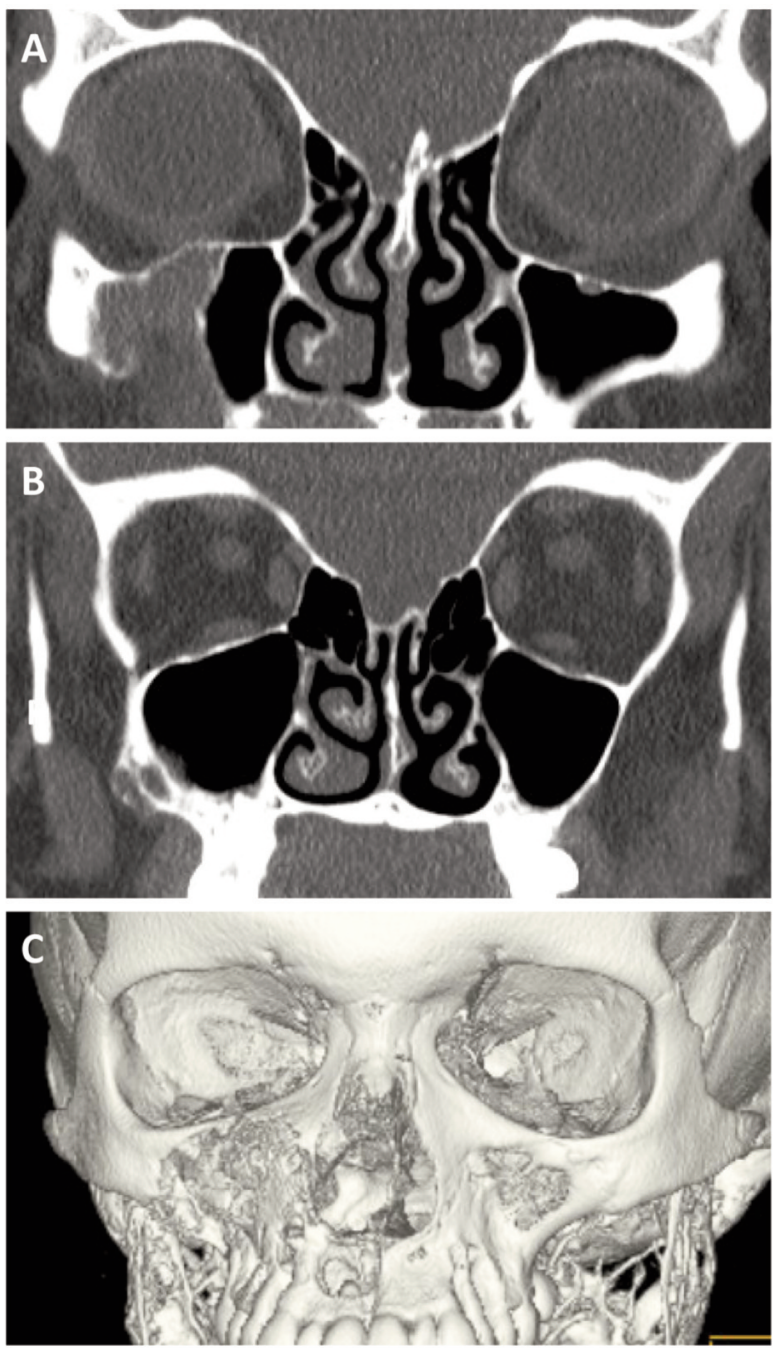

Figure 3. Cone beam computed tomography of midfacial region in a patient with NF1 and cherubism-like phenotype. (A) The coronal projection shows the deformation of the orbital floor on the right side, intact orbital floor and soft tissue tumor present directly adjacent to the bone at this site. $(B)$ The superior, medial, and lateral borders of the orbits have developed symmetrically. The lesion infiltrates the lateral maxillary sinus wall on the right side. A small, circumscribed soft tissue-equivalent radio-translucent lesion complementary to the bone lesion bulges in the right maxillary sinus. However, the entire sinus system is ventilated. (C) In the surface reconstruction of the midface bones, the extensive osteolysis on both sides becomes evident. The figure illustrates the asymmetry of the orbit at the entrance, which is characterized by a narrower vertical dimension and an approximately horizontally oriented oval compared to the unaffected left side.

indicating diffuse involvement of facial soft tissues (Figure 2). A computed tomography (CT) made 9 months after the first jaw surgery revealed bilateral bubble-like lesions of the mandibular branches and destruction of the bone below the alveolar process. On both sides, the mandibular capitulum's articular surface remains spared from the lesion. Bubble-like 

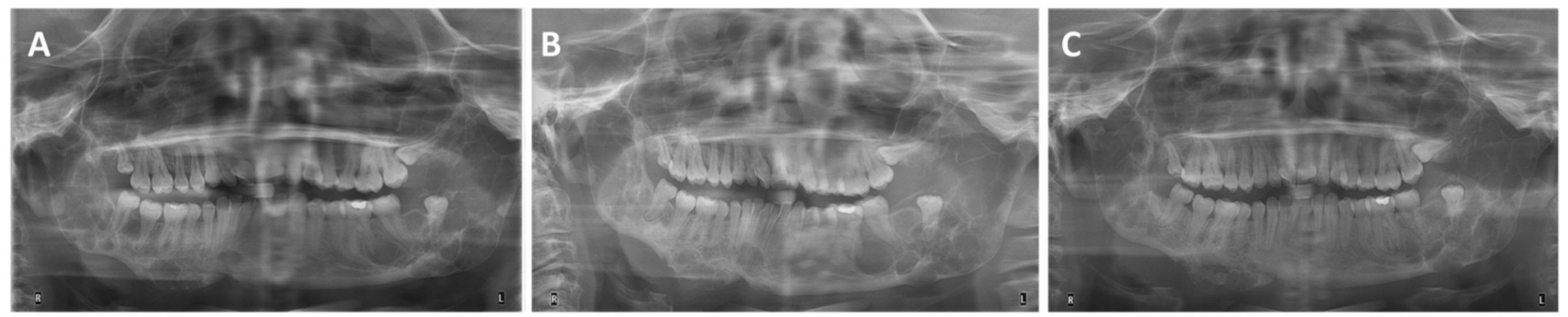

4.2013

4.2014
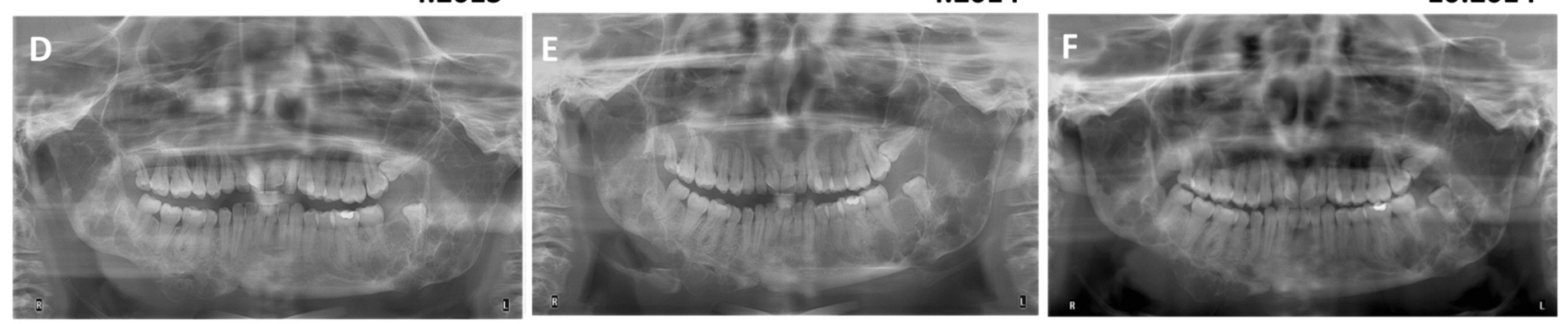

8.2015

4.2016

12.2016

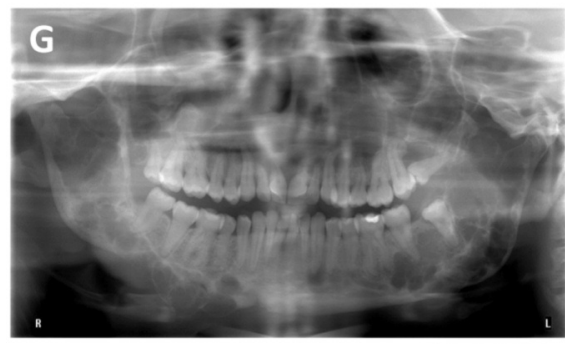

10.2017

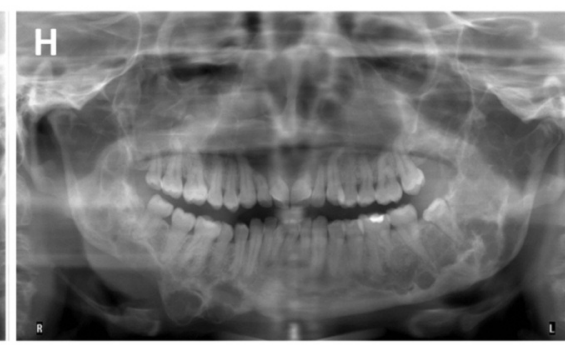

26.11.2019

Figure 4. A series of panoramic views illustrates bone remodeling in a patient with NF1 and cherubism-like phenotype during a period of six and a half years. (A) Extensive, inhomogeneous osteolysis of the jaws with intact radiological morphology of the teeth. When comparing Figure (A) to (C), the bubble-like osteolysis of the mandibular angle and apical region of the inferior right wisdom tooth 48 was conspicuous at the initial examination (A). However, the bone re-ossifies in the further course following surgical reduction of $C G C G(B, C)$. On the other hand, the osteolysis around the lower left second molar increased in size within three years $(D-G)$, without any effect on tooth position and integrity. However, within a further two years, the bone ossified, especially in the interradicular area of teeth 36 and 37 and further caudal to these molars. The tilting of the retained tooth 38 and the wisdom tooth' approximation to the second molar took place at the end of the osteolytic phase and continued during the consolidation phase of the bone in the left jaw angle $(G, H)$. The sequence of the X-ray images $(A-H)$ shows that repeated curettage of the tumor from the right-sided basal expansion of the lower jaw had no long-lasting effect on bone shape.

lesions of the entire maxilla are just affecting the orbital floor without invading into the orbital cavity. The paranasal sinuses have no swelling of the mucous membrane and are filled with air. Radiological findings of the skull are compatible with a case of cherubism (Figure 3). The panoramic views of the jaws taken during the treatment showed the bone remodeling of the jaws affected by the CGCG, especially in the lower jaw (Figure 4).

Teeth. The patient has a fully developed permanent dentition (Figures $1 \mathrm{~F}$ and 4). The right upper wisdom tooth is micromorphic; the left upper and lower wisdom teeth are retained. Except for retained wisdom teeth, all permanent teeth are completely erupted and in occlusal contact with antagonists. Except for retained wisdom teeth, all teeth have approximal contact to neighbors, an important clinical difference to many cases with trigeminal nerve plexiform neurofibroma. The lower left wisdom tooth is considerably distalized compared to the second molar. The space between the two teeth is filled with a cyst-like radiotranslucent lesion. MRI taken at the age of 16 showed cyst-like changes of the roots of teeth 11 and 12 .

In the further course of the outpatient treatment, the patient reported to have had a head accident, hitting on the upper front teeth at the age of 18 . Since then, the right central incisor has been slightly loosened. However, during the next three years, the left central incisor responded to adequate cold stimuli. Lateral root resorption of the upper 

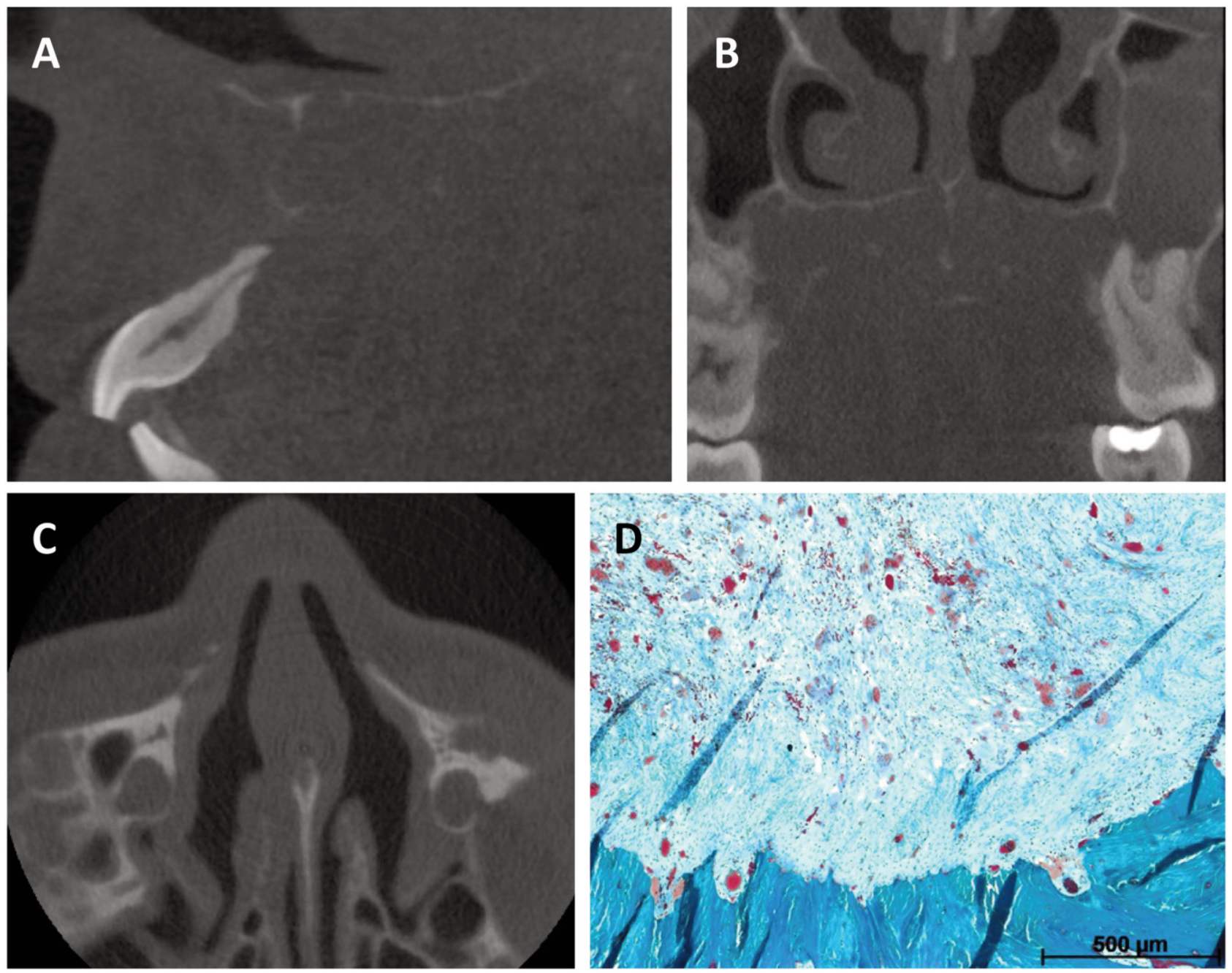

Figure 5. Cone beam computed tomograms of maxilla in a patient with NF1 and cherubism-like phenotype. Figure (A) shows the traumatized tooth 11, which developed resorptions of the root after repositioning and integration in the dental arch. Bone-isointense radiopacity is almost completely absent in the anterior dentoalveolar area and only shown in continuity in narrow traces on the floor of the nose. (B) Extensive osteolysis of the maxilla extends to the floor of the nose on both sides, and a thin line of alveolar bone is evident around the molars, without the internal framework of the skeleton being destroyed $(C)$. (D) The histological image shows the invasive growth of the lesion with prominent osteoclasts at the interface between the lesion and bone (Goldner staining).

central incisors could be demonstrated on X-rays (Figure 5). Later, the teeth were anchored somewhat more firmly in the bone and no longer sensitive to chewing and biting forces, thus posttraumatic ankylosis is assumed.

Skin. The skin is covered with densely spread punctiform brownish hyperpigmented maculae of few millimeters in diameter. Multiple CAL spots have developed, predominantly on the trunk (Figure 1A and C). Freckling of the skin is noted in the axillary and inguinal regions. Since puberty, some scattered cutaneous neurofibromas have developed in the skin, especially of the trunk and extremities, and in the chin and frontal region. The patient has developed a hyperpigmented, flat skin tumor of the right forearm (Figure 1D and E). The tumor has been known since early childhood. This tumor was assessed as a diffuse neurofibroma. The patient reports that generalized itching is difficult to control.

Therapy of cutaneous neurofibroma. Several cutaneous neurofibromas were removed over the course of 8 years. Wound healing always proceeded in regular phases with complete restoration of the integument. The scars are at the level of the skin: no keloids have occurred. There are no local tumor recurrences. The histological picture of the lesions is uniform. The tumor cells are S100 positive. Antibodies against 
epithelial membrane antigen (EMA) and neurofilament identify several small nerve fascicles, some of which are also located in the tumor and were possibly invaded by tumor [Ki67 index $3.5 \%\left(8 / 227\right.$ counted cells $\left.\left./ \mathrm{mm}^{2}\right)\right]$.

Therapy of diffuse neurofibroma. At the age of 14, the tumor of the right arm increased in volume and was resected. Healing was uneventful. However, the tumor rapidly recurred and a further tumor reduction was carried out at the age of 16. The surgical measure achieved normal contouring of the hyperpigmented body region. The treatment result remained stable in the following years until, at the age of 22 recurrent lobular tumor formation was found to be disturbing in daily physical activity. Therefore, a further tumor reduction was performed. This tumor was predominantly a diffuse neurofibroma with circumscribed regions of plexiform differentiation (Figure 8).

Brain. Cranial MRI disclosed focal areas of signal intensity (FASI) in different regions of the brain, e.g. callosal commissure, mesencephalon, in the basal ganglia and the cerebellar core areas. However, the comparison of findings recorded over several years indicated that the regions demarcate with varying degrees of intensity and are not constant in extent and localization over time. The patient did not develop optic pathway glioma.

Endocrine and exocrine functions. In the early postnatal period, hypothyroidism was diagnosed and treated with levothyroxine up to the age of 13 . On admission, the basal value of thyroid stimulating hormone (TSH) was in the normal range in the hormone-substituted patient (3.00 $\mathrm{mIU} / \mathrm{l})$. Repeated determination of parathyroid hormone showed normal values. The patient has been taking several vitamins for substitution since her early youth. However, the regular intake of the substitute was repeatedly interrupted for some time due to the patient's lack of compliance, as the mother reported. Various metabolites of vitamin $\mathrm{D}_{3}$ were determined, and values were in the normal range. Serum calcium, sodium and phosphorus levels were in the normal range. However, repeatedly measured serum value of alkaline phosphatase was increased.

Liver enzyme values are increased since birth, but there are no synthesis disorders (GOT $73 \mu / 1$; GPT $75 \mu / 1, \gamma$ GT $116 \mu / 1)$. Current B-scan ultrasound of the adult patient's liver (diameter $10.9 \mathrm{~cm}$ ) showed slightly enlarged bile ducts of the left lobe and atypical course of lienal vein. Serum creatinine value was normal, but GFR increased according to chronic kidney disease epidemiology collaboration (CKDEPI) calculation (130.7).

Long bone lesions: Imaging and therapy. On admission, the patient is short (148 cm body height) and body weight is low
$(42.5 \mathrm{~kg})$ [Deviation from the developmental norm (percentile (perc.)): height $=1$. perc. $(=-2.75$ standard deviation (SD)); weight $=1$. perc $(=-2.22$ SD)]. Previous $\mathrm{X}$-ray findings of the spine describe pronounced lumbosacral hyperlordosis $\left(90^{\circ}\right)$, without evidence of scoliosis. During the first examination of the patient, the inclined pelvis was noticed (Figure 1D). The patient has no butterfly-like vertebrae on spine radiographs. At the age of 11, the patient fell from a height of about 2 meters and the right ala ossis ilii fractured. There was also an infracture of the left acetabulum. The non-displaced fractures were treated conservatively. X-ray findings of the long bones from the time of pelvic fracture diagnosis are unknown. There are no post-traumatic complaints in this region related to the bones. There is a leg length difference in favor of the right side of 1.6 centimeters. At about 14 years of age, the patient developed non-specific complaints of the knees and right elbow. X-rays of the knee joints showed multiple fibrous cortical defects of the distal femoral metaphysis and proximal tibial metaphysis on both sides, possibly including the proximal fibula on the left side. The radiological findings were assessed as NF1-associated bone defects, which are to be stabilized surgically (Figure 6). A whole-body MRI was performed to determine the number of bony lesions and the general tumor load. Whole body MRI showed patient's low internal tumor burden. A few cutaneous neurofibromas and the well-known neurogenic tumor of the right forearm were visible on MRI. Multiple nodular tumors of the parapharyngeal space of both sides were arranged like a string of pearls (Figure 2A).

Additional findings were extensive bone lesions of the metaphysis of distal femora and proximal tibiae (only vaguely visible on the left tibia). Additional CT scans of the region showed that the lesions had not caused a cortical defect. The diagnosis of the bone lesions was initially not obvious. Because of the local pain, exploration, curettage and elastic stable intramedullary nailing of the right distal femur and curettage of right proximal tibia were carried out. Alloplastic bone replacement (ceramics) was inserted in the right femur. Healing was uneventful. There have been complaints of the spine since the age of 17 , for which no cause has yet been identified.

Long bones lesions: Histology. The first assessment of the bone samples gave the following findings: Right Femur: Fibrous metaphyseal defect with proliferating mesenchymal cells, multinucleated giant cells, and residues from older hemorrhages in the bones. Tibia: Bone specimen with partially fibrosed connective tissue without inflammation, initially suspected of a solitary bone cyst.

The finding was re-evaluated now considering the syndromic background and rated as membranous-cystic tissue, partially monomorphic, mononuclear stroma with 

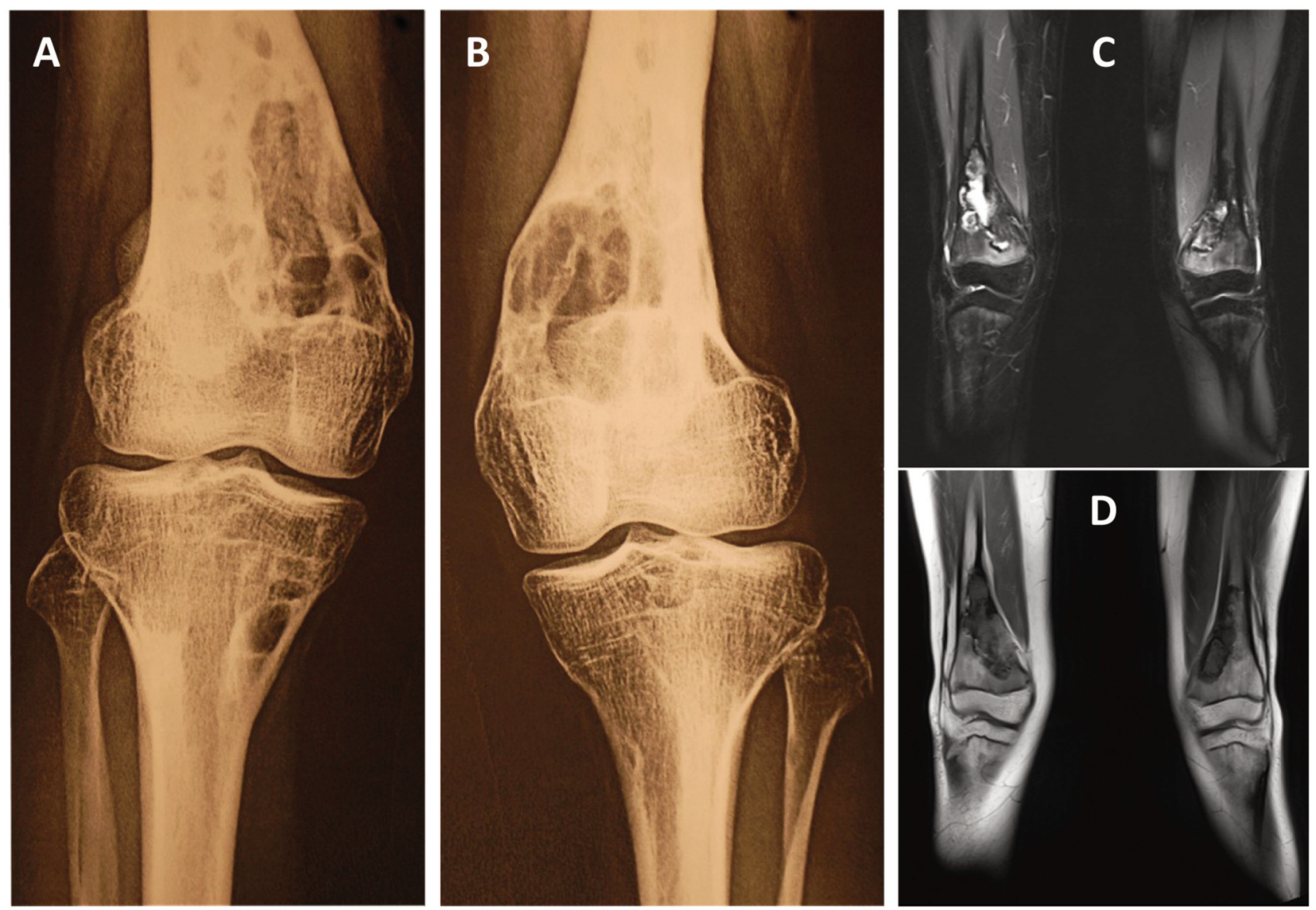

Figure 6. Radiological findings of bilateral non-ossifying fibroma of lower extremities. (A) and (B) Plain radiographs of the distal femur, upper tibia and fibula region depict an oval subcortical radio-translucent lesion in both the femora and right tibia adjacent to epiphyses. Lesions present with a sclerotic margin. In the region of maximum horizontal diameter of both femoral lesions, the contour of the bone appears somewhat bulging outwards. On magnetic resonance imaging $(C$ and $D)$, hyperintense lesions of the femora are prominent on T2-weighted images $(C) . T 1$ weighted images show intact cortical layer of the bones.

numerous residues of hemorrhages. A loose, myxoid foreign material was focally disseminated. In further sections of the specimen, multinucleated osteoclast-like giant cells could be seen in the fibrous stroma and distinct small areas with bone necrosis. The initially favored diagnosis of an aneurysmatic bone cyst, based on a giant cell tumor, was corrected. The bone findings of the extremities resembled jaw lesions in patients with cherubism. The final histological and radiological assessment of long bone lesions favored a case of Jaffe-Campanacci syndrome (JCS) as a rare NF1 phenotype due to NOF of the long bones in combination with multiple osteolysis of the jaws.

Genetics. The patient's genetic basis of NF1 was first revealed at the age of 10. The deletion of an adenine residue in the cDNA sequence at position 97 (97delA) of exon 2 of the NF1 gene was detected in the patient's blood. The mutation is a frameshift mutation that causes an early stop codon at amino acid position 43 . The termination of protein was predicted to result in a very shortened, non-functional neurofibromin polypeptide. The mutation of the NFl gene is causative of the disease NF1.

In the current genetic investigation, the already known germline mutation was determined according to $\mathrm{HGV}$ sequence nomenclature as c.99delA; p.Val34Serf*10 in the blood DNA (18M0623), in a neurofibroma (18M0629) and in central giant cell granuloma of the jaw (18M0627). A second hit was detected in the neurofibroma's DNA (18M0629). There was a deletion of the entire NF1 gene in the second allele of the nerve sheath tumor of the right upper extremity. However, the DNA of the giant cell granuloma (18M0627) showed no NF1 deletion or any other mutation of the allelic $N F 1$ gene. Similarly, despite deep sequencing $(\times 500)$, no mutations in other RAS 

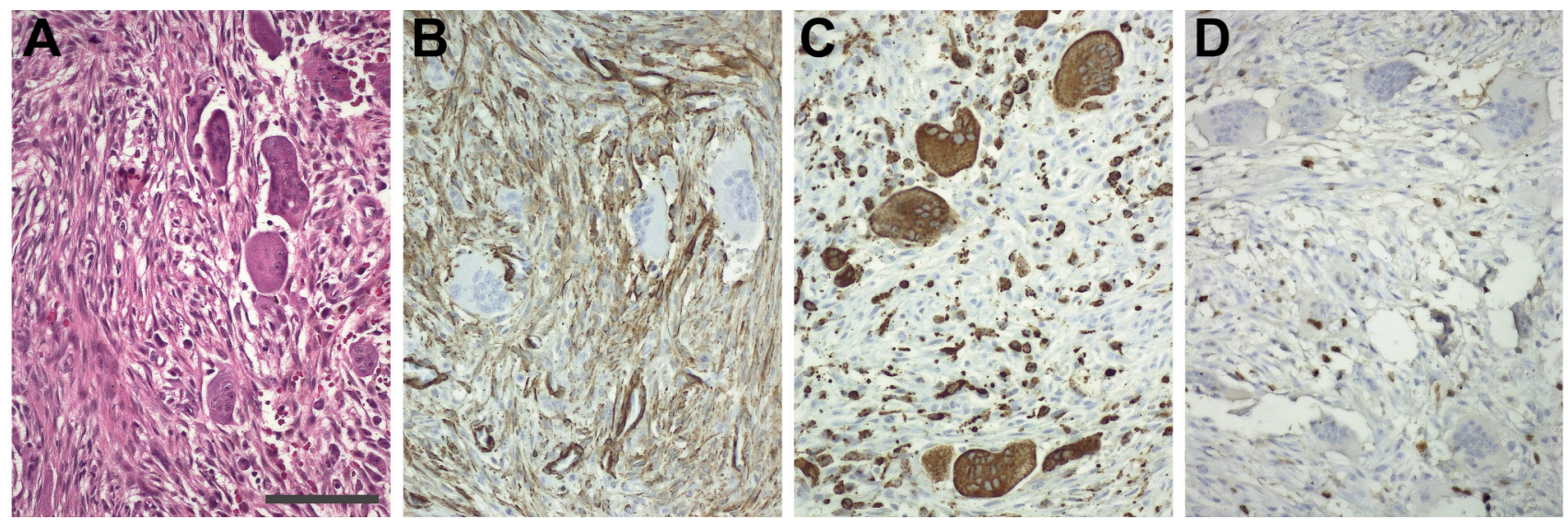

Figure 7. Histology of CGCG. Giant cell granuloma in neurofibromatosis 1: (A) hematoxylin and eosin (H\&E) stain reveals a proliferation of spindle cells intermingled with small histiocytic elements and giant cells; (B) immunohistochemically demonstration of smooth muscle actin (SMA, brown stain) in spindle cells (not shown: expression of vimentin, no expression of S100 protein, EMA, CD34 and desmin); (C) demonstration of CD68 in small histiocytic elements and giant cells; $(D)$ demonstration of a proliferation index of $5.8 \%$ in fibrohistiocytes using Ki67-antibodies, no labelling of giant cells; scale in $(A)=100 \mu \mathrm{m}$ also applies for pictures $(B-D)$.

pathway genes were detected (multigene panel). The detection threshold of the examination procedure was $1-2 \%$ in the mosaic part of a lesion. The RNA analysis of the giant cell granuloma showed no evidence of an aberrant transcript. In a further investigation, it was examined whether a loss of heterozygosity $(\mathrm{LOH})$ of the $N F 1$ gene could be detected in formalin-fixed, paraffin-embedded samples of the CGCG. No LOH of the NFI gene was detected. Comparative exome sequencing showed no interesting somatic variant in a plausible candidate gene for the development of a giant cell granuloma, especially not in SH3BP2 (comparison of the blood DNA as a surrogate of the germline mutation $v s$. extract of the giant cell granuloma).

Analysis of JAG1 and NOTCH1 genes revealed no mutations known for ALGS. However, a hitherto not described heterozygous $J A G 1$ variant (c.575A>G) (p.Tyr192Cys) was identified in the blood and tumor tissue (CGCG).

Therapy and follow-up of CGCG. Under general anesthesia, the extensive CGCG of the upper and lower jaw were excised (REF). At the infraorbital margin, the tumor had expanded far anteriorly. With the removal, the infraorbital rim could be permanently reshaped. The treatment result of the orbital region has remained stable for 5 years. In contrast, the excised extensive CGCG on the right side of the mandible recurred soon after surgery to the former size. The administration of bisphosphonates or other inhibitors of bone metabolism, that have been recently propagated for the treatment of CGCG, was not applied due to the patient's many illnesses. The extraction of a partially retained tooth healed without complications.
Histology of jaw lesions. The spindle cell component of the bone lesion expressed actin. The giant cells (osteoclasts) were CD68 positive. The lesion showed no reaction to antibodies against S-100 protein, epithelial membrane antigen (EMA), desmin, CD34 and neurofilament. The antibody against $\mathrm{Ki} 67$ did not react in the giant cells. In contrast, Ki67 index was 5.8\% (10/171 counted cells $\left./ \mathrm{mm}^{2}\right)$ in the proliferating spindle cell component of the lesions. The vessels of the granular lesions showed no perivascular cuffing. Oral biopsy of soft tissues covering the partially retained teeth adjacent to the bone lesions showed unremarkable mucosa without evidence of infiltrates of a neurofibroma. Neither progesterone nor estrogen receptor expression was identified in samples of the jaw lesions (Figure 7).

\section{Discussion}

This case report describes the diagnosis and treatment of various skeletal and soft tissue manifestations in a patient with NF1 who is also affected by other diseases that can influence the facial phenotype and bone metabolism. Knowledge about the diseases has influenced the choice of therapeutic measures. The course of treatment documents the successful alleviation of some symptoms through individually adapted medical and surgical measures and the importance of pathological and genetic diagnostics for the patient's care.

NF1 and bone. NF1 is known for the characteristic peripheral nerve sheath tumors, but is also a disease of the skeleton $(8,9)$. Certain local skeletal malformations are 

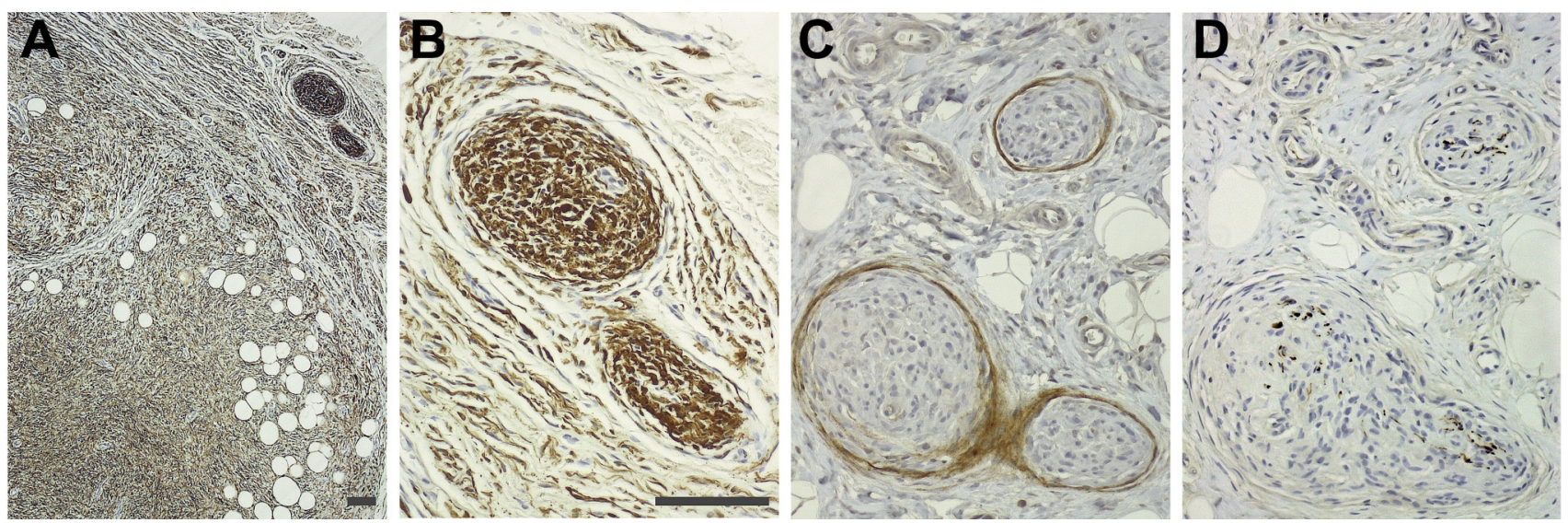

Figure 8. Dermal neurofibroma with predominantly diffuse growth and scattered intraneural plexiform tumor parts: (A) over-view depicting a diffusely growing tumor composed of cells expressing $\$ 100$ protein (brown stain) with occasional circumscribed tumor areas indicating intraneural growth (upper right); (B) S100 protein immunohistochemistry as in A, demonstrating the plexiform tumor portion at a higher magnification; (C) demonstration of an intact perineurium surrounding the intraneural tumor parts with antibodies against epithelial membrane antigen (ring shaped brown stain); $(D)$ detection of scattered residual axons within the plexiform tumor areas with antibodies against neurofilament (brown dots); scale bars in $A$ and $B=100 \mu m$, scale in $B$ also applies for $C$ and $D$.

among the pioneering findings in the clinical diagnosis of NF1 (1). Skeletal manifestations of NF1 can affect the entire system (osteoporosis, short stature) but also can cause local disorders concerning the shape and function of bones (pseudarthrosis, scoliosis, dysplasia of the skull) (2). While general disorders of the skeletal system affect many NF1 patients (2), local bone malformations and defects such as sphenoid bone dysplasia or mandibular lesions are less frequently recorded $(1,10-12)$. The rare finding of local bone enlargement in NF1 patients is usually observed in association with congenital plexiform neurofibroma. Preferentially long bones are affected $(2,13)$, but local hypertrophy can affect almost any bone. Unilateral facial enlargements are typical findings of NF1 patients associated with trigeminal plexiform neurofibroma (PNF). Contrary to the external impression of a one-sided facial hyperplasia, the mandible adjacent to the tumor is usually hypoplastic and distortion of maxilla is forced by tumor-associated scoliosis (14). For most patients, the unilateral increase in facial volume is the result of nerve sheath tumor growth. True local hypertrophies of the jaw, especially the mandible, have rarely been reported in NF1 (15) and the topographical relation with a PNF needs to be examined in the individual case (16). So far, the causes of bone dysplasia in NF1 are unknown and are very likely multifactorial $(8,9)$. Haploinsufficiency and LOH of the NF1 gene are important factors in local skeletal disorders of NF1 patients $(17,18)$. In the present case, osteogenic hyperplasia of both jaws is evidently associated with extension of multilocular, 'bubbly' lesions of osseous origin. There is no adjacent facial PNF. Nerve sheath tumors can develop in the jaws (19-21).
However, neurofibromas rarely develop in the jaws of NF1 patients (12). In rare cases, malignant peripheral nerve sheath tumor (MPNST) arises in the bone (22). Genuinely osseous lesions other than CGCG can also develop in NF1 (12). Therefore, providing histological diagnosis is indicated for osseous lesions in NF1.

Central giant cell granuloma of jaws (CGCG). CGCG is a tumor-like lesion in the jawbone of unknown etiology and pathogenesis $(23,24)$.

Differential diagnosis and terminology. CGCG has been classified as a non-neoplastic lesion almost exclusively arising in the jaws (25). The histological features of CGCG do not correspond to those of a granuloma as such (25). It was therefore proposed to use the term giant cell lesion of the jaw (GCLJ) or central giant cell lesion (CGCL) (of jaw) as an alternative term (26-28). However, both old and new terms are currently used to address this entity $(29,30)$.

CGCG as a jaw lesion (31) must be differentiated from other bone lesions with prominent giant cells, e.g. the giant cell tumor (GCT) of the extragnathic skeleton, arising particularly in long bones (32-34). Both entities show similar morphology $(25,35-37)$. For a long time, it was discussed that gnathic (CGCG) and extragnathic lesions (GCT) with a granuloma-like morphology constitute locally modified variants of a common entity (25). The distinction between the two bone lesions was suggested by morphological and clinical studies (31) and finally achieved in modern genetic tests (38, 39). Another important differential diagnosis of the CGCG is the fibrous metaphyseal cortical defect [synonym: NOF (of 
long bones)]. CGCG [outdated synonym: 'reparative' giant cell granuloma of the jaw (31)] and NOF are histologically identical. Tissue sections from GCT can have individual areas giving the impression of a NOF, thus differential diagnosis of lesions can be difficult (25). However, the jaw lesion can be clearly distinguished from the giant cell granuloma-like lesion of the extremities by localization and X-ray findings (25). Problems in correctly diagnosing bone lesions in NF1 can arise if an individual develops osteolytic lesions both in the jaw and in the long bones, the former one indicative of CGCG and the latter of GCT, NOF or other types of non-ossifying bone lesions $(40,41)$.

Incidence and clinical findings of CGCG. Knowledge of the incidence of CGCG refers to an epidemiological study by de Lange et al. (2004) in the Netherlands (29). Incidence is about 1.05/1 million in males and 1.35/1 million in females (29). CGCG may arise in every age group, however, preferentially arise in younger individuals ( $<30$ years), more often in women, and twice as often in the lower jaw compared to the upper jaw. Treatment is surgical (curettage). Clinical findings in CGCG are variable. Usually, there is a solitary, painless, slowly growing lesion of the jawbone (29). However, radiological findings vary from small, unilocular to large, multilocular lesions with tooth displacement or root resorption. Lesion-associated paresthesia is rarely recorded (25). Recurrence rate is variable (11\% to $49 \%$ ) and relatively high concerning a benign lesion.

Cells of origin in CGCG. The typical multinuclear giant cells of the lesion are part of the body's response to the causative pathogen(s) and have been identified as osteoclasts (42). The CGCG's proliferating and tissuedegrading cells are small, isomorphic cells with a prominent, compact nucleus surrounded by a narrow perinuclear cytoplasm (43). The discussion about the biological characteristics of the constituent cells of the lesion goes back to the time of the nosological demarcation of the lesion (25), when the unifying concept for these jaw lesions was established: the term 'CGCG' apparently includes a wide range of entities, with reactive lesions [e.g. in cases with hyperparathyroidism (44)] on the one side and tumor-like aggressive osteolytic findings of jaws (45) on the other side of spectrum. It is well known that bone lesions in hyperparathyroidism can lead to metaphyseal defects of the long bones as well as CGCG $(46,47)$.

CGCG and syndromes. Most CGCG arise without known systemic disease and are considered a sporadic lesion $(25,29)$. However, CGCG is an optional finding of various syndromes, such as Noonan syndrome $(48,49)$, cardio-facio-cutaneous syndrome (50), oculoectodermal syndrome $(51,52)$, NF1 [5363 , including peripheral giant cell granuloma (56)], and
Schimmelpenning syndrome (64). CGCG was noted in a case with Turner syndrome (65). Multiple CGCG of the jaws are rare and give rise to suspicion of a generalized disease (43, $44,63,61)$. However, the finding of a solitary CGCG does not exclude a syndromic background of the lesion (60).

CGCG of jaws in NF1. CGCG is an unusual, well-known lesion of the jaws in NF1 $(31,55,57)$. However, the number of NF1 patients is low in studies regarding this jaw lesion $(29,30)$. In a group of 83 patients with CGCG, there were 2 patients with proven NF1 (2.41\%) (29). The total case number of extensive NF1-associated CGCG was slightly more than 10 in a recent review of reports published in English (41). Indeed, the association between CGCG and some cases of NF1 is apparently largely unknown (66). Recently, LOH of the NFI gene was identified in the recurrent mandibular CGCG of an NF1 patient (60). An extensive study revealed the second (somatic) hit of the $N F 1$ gene in the tumorous cells of NF1-associated CGCG in two cases (67). This finding was confirmed in a further NF1associated multilocular mandibular CGCG (63). Genetic test results on constitutive mutations and on CGCG (67) have made a significant contribution to clarifying the interpretation of clinical-radiological findings [unilocular vs. multilocular, synchronous vs. metachronous (68)] for the definition of entities arising in the jaws being rich in giant cells (69).

However, no somatic NF1 mutation in the CGCG was detected in the present study. This result is in contrast to previous studies on CGCG and NF1. Other known mutations of the RAS pathway were not detected in this CGCG either.

However, second hit mutations of NFI gene were not identified in NF1-associated NOF of long bones despite using very sensitive detection methods (67). This result indicates that either (genetic) factors independent of a second hit of the NFI allele can initiate the osteolytic bone lesion, or the proportion of tumor cells with a somatic mutation of $N F 1$ gene in a lesion can be very low but very effective and thus, have a 'large-volume' effect inducing dedifferentiation of neighboring cells. The term 'landscaping effect' was introduced for this hypothetical impact of cells or cell groups on surrounding non-tumorous cells (69).

Non-ossifying fibroma (NOF) of the bone. NOFs are a common finding in long bones (31). The lesions develop preferentially in childhood and adolescence, are usually nonsymptomatic, and diagnosed as incidental findings on $\mathrm{X}$ rays. It is believed that approximately $30 \%$ of children and adolescents have NOFs of long bones (70). The lesion is frequently localized around the metaphysis $(31,71)$. Lesions of the distal femur are characteristic among the NOFaffected bones (31). Growth potential of NOF usually is selflimiting, giving the impression of a small, sharply demarcated cortical defect of cortico-cancellous lesion 
restricted to the metaphyseal regions, or a scalloping osteolytic lesion covered with a thin cortical layer. Many lesions heal with complete bone recontouring of the trabecular and cortical bone. Small, local contour changes or hyperdense areas of a former NOF region can indicate residues of the lesions on plain radiographs. However, in some cases the lesions can be symptomatic requiring surgical intervention $(71,72)$. A clinical study identified $12.6 \%$ of cases that had been symptomatic and 6 of 87 cases $(6.9 \%)$ even had developed a lower extremity fracture (73). Some authors differentiate between the fibrous metaphyseal defect and NOF of long bones (74). Generally, both non-ossifying lesions of the metaphyseal long bones are considered variations of a uniform pathogenesis (70). Since NOF is typically a self-limiting lesion with a high spontaneous healing rate, there has been controversy over a long time whether these lesions are malformations or neoplasms of the skeleton. Somatic KRAS mutations were identified in $64 \%$ of 59 evaluated cases of NOFs of the bone (75). NOF is regarded a RAS-MAPK driven benign bone neoplasm (76). Other mutations have been identified in NOFs in the FGFRl gene (69).

No tissue sample from the NOF of the patient was available for examinations, so reference is made to the literature review for the interpretation of the findings (69).

NOF of the bone in NF1. NOF of the long bones develop in some NF1 patients $(40,77-81)$. The frequency of the lesions in NF1 is unknown and clinical studies on NOFs usually do not present information about the genetic status of the patients $(73,74)$. Pathological fractures in NF1-associated NOF have been reported that had to be treated with osteosynthesis $(78,82)$. Combinations of NF1 with NOF and another syndrome are known (83). NOF also occurs in syndromes not related to NF1 (84-86). The differential diagnosis of NF1-associated NOF to other osseous lesions can be difficult (87-89), even when using very sophisticated methods detecting differences in the metabolism of the lesion indicative for a malignant neoplasm $(90,91)$. Complete radiological examination of the skeletons of NF1 patients is not part of the diagnostic routine for this patient group (2). It is assumed that the proportion of undiagnosed metaphyseal lesions of the long bones in NF1 patients can be relatively high and the diagnosis of NF1 should be considered in the case of multiple multi-cystic lesions localized around the knee (92). Diagnostic biopsies were considered unnecessary in these cases (92). However, surgical exploration may be necessary if the differential diagnosis of imaging findings is inconclusive $(84,90)$ or the patient develops local symptoms $(22,89,91,93)$. On the other hand, it is known from wholebody (WB) MRI of 247 patients with neurofibromatosis that NOF is detected in around $1.2 \%$ of cases (94). However, the information relates to the entire group of patients who either had NF1 ( $\mathrm{n}=141), \mathrm{NF} 2$ or schwannomatosis. In addition, the study focused on patients $>18$ years old and thus, not on children and adolescents, in whom the prevalence of the lesions could be higher. The resolution quality of WB MRI for small bone lesions is also unknown. Nonetheless, the study suggests that long bone lesions are likely to be rare in adult NF1 patients and do not differ from the general population (95).

Current recommendations for imaging NF1 focus on internal tumor detection, especially soft tumors, when using WB MRI. The differentiation between benign, potential malignant, and malignant tumors is in the foreground of the application. Skeletal lesions are not the focus of the application of non-radiogenic overview examinations of the NF1 patient. Localized imaging strategy adapted to the situation is recommended for symptomatic findings (96).

Association of CGCG and NOF. Both sporadic NOF of the long bones and sporadic CGCG of the jaws share mutations in the KRAS and FGFRl genes (69). However, mutations in TRPV4 were identified in CGCG but not in NOF. The mutation pattern of sporadic CGCG so far has not been confirmed for syndrome-associated osteoclast-rich lesions of the craniofacial bones. In NF1-associated osteoclast-rich lesions of the craniofacial bones, only mutations of the NF1 gene can be regarded as the presently known cause for the lesion(s) (69).

Jaffe-Campanacci syndrome. In some cases, patients develop NOF in the long bones and show extra-skeletal findings, in particular hyperpigmentation disorders of the skin, such as CAL spots and inguinal/axillary freckling (97-99). However, these patients do not develop neurofibromas (97-99). The first description of the combination of the skeletal and cutaneous findings goes back to Jaffe. He had already discussed the phenotype as a forme fruste of neurofibromatosis (99). Twenty years later, Campanacci gave a lecture presenting detailed case reports and literature review of the combination of long bone lesions and pigmentation disorders (97). Following this oral presentation, the coincidence of non-ossifying fibrous lesions of long bones and pigmentation disorders of skin (and further 'extra skeletal' findings, with mandatory exclusion of neurofibroma) was interpreted as a distinct syndrome (97, 98). Referring to the mentioned Campanacci lecture reporting 4 cases of NOF and CAL spots, Mirra et al. added another case with this combination of findings (97). This report mentions for the first time in writing that three of the four Campanacci's cases had also developed jaw lesions. Neither in this nor in later reports the jaw lesions' diagnosis is clarified, thus assessment of the jaw lesions of Campanacci's original report cannot be made from available documents. A tissue sample of jaw lesions was not taken in 
any of the cases (97). Thus, the case report by Mirra et al. (97) is the first, in which all three findings were adequately documented (skin finding, metaphyseal bone defect, mandible defect) and a tissue sample of the mandibular lesion was examined in detail. The histological finding was CGCG of the jaws. The almost complete identity of the lesions' histological findings in the long bones and the jaws was explicitly mentioned. The designation 'JaffeCampanacci syndrome' (JCS) was introduced to describe patients with both skeletal and cutaneous findings giving reference to authors contributing to the delineation of the syndrome as a clinical entity (97). In the clinical research following this first description, the skin findings and the metaphyseal osteolysis were used as the essentially defining features of the syndrome ('classical' JCS) but not the jaw findings (67). Indeed, osteolytic jaw findings have only been reported in a few cases of JCS (for review: 67). A possible cause for this selection of pathfinding diagnostics in JCS may be that in the case where NOFs on X-rays of the long bones are identified, simultaneous cranial X-ray diagnosis is not mandatory. On the other hand, if a CGCG of the jaw is detected in an individual, $\mathrm{X}$-ray diagnosis of the extremities is not a routine standard. The definition of constitutive features of JCS, in particular the importance of the jaw lesions, is also made more difficult by the fact that Campanacci does not mention any case with lesions of the jaw in a later presentation of the syndrome of multiple NOFs of the long bones and pigmentation disorders of the skin $(n=10)$ (99). However, the report appreciates several other findings associated with the syndrome (98). None of the patients had neurofibromatosis or had family members with this diagnosis as revealed in long-term follow-up (100). Of note, current NF1 diagnostic criteria (Table I) do not cover all potentially affected individuals under 8 years of age (101). If the patients who were supervised by Campanacci for a long time did not develop NF1 (100), genetic mosaic of NF1 must also be considered for the assessment (67).

Extra-skeletal findings in JCS remain very variable. The skin findings are inaccurately described and classified as part of the syndrome with very variable appearance and different morphology. CAL spots were recorded in only 6 out of 10 patients (98). In a later analysis of a large series of NOF including 20 cases with JCS, no indication of skull findings is given either (100).

In the time between the two reports by Campanacci (98, $100)$, Mirra published a review on the syndrome, which he himself has named (102). In fact, the application of diagnostic standards was made even more difficult by this overview. First, the data reported to date (1989) on JCS were summarized, based on the referred 10 cases by Campanacci (98) and one by Mirra et al. (97). Then, a new case was added, which was presented as atypical, but was claimed to meet JCS diagnostic criteria. In this case, the maxilla and mandible were affected by CGCG. The long bones were explicitly described as not affected. Multiple nevi were registered as skin findings, which were histologically found to be incontinentia pigmenti (no CAL spots). However, there were also pits in the skin folds (axilla). The differential diagnosis (103) of the presented findings of a mentally handicapped 9-year-old patient was not discussed, neither concerning skin findings nor multiple CGCG in the jaws, presumably because the analysis was devoted to reviewing skeletal findings, in particular the morphological identity of NOF and CGCG. Subsequent studies on multiple CGCG without evidence of NOF in the long bones usually have refrained from evaluating skin and jaw findings as sufficient for diagnosing JCS, with few exceptions (67).

$\mathrm{JCS}$ is a rare diagnosis in collective statistics on fibrous cortical defects/NOF of long bones [e.g. 2/401 cases, $0.5 \%$ (74)] and is not regularly considered a differential diagnosis in the standardized treatment evaluation of metaphyseal NOF (73). The description of JCS predominantly from X-ray and morphological findings of the axis skeleton and the inspection of the skin have consequences for the further application of JCS diagnosis in medical literature. In many reports on metaphyseal defects of the long bones diagnosed as JCS, investigation of the jaws is not reported and CGCG is not a constitutive finding to distinguish sporadic and syndromic lesions (67). As a rule, jaw findings are not considered in recent case reports on JCS (104-109).

In other words, CGCG of the jaw is not a defining feature in diagnosing JCS in recent radiological, orthopedic, and genetic literature $(67,79)$. In individual cases, pigmentation disorders like those of NF1 patients and NOF can also develop in patients affected with other syndromes (109). Among other diagnoses of bone lesions (see above), differential diagnosis of NOF is fibrous dysplasia and osteofibrous dysplasia Campanacci $(110,111)$, the latter one with preference for the tibial cortex (31). Differentiating the entities can be difficult, especially for small tissue samples and for samples taken from patients in whom the bone findings have already been treated surgically. The genetic basis of the syndrome is unknown. However, most cases with features of JCS of the recent past are diagnosed as having NF1 (67).

Jaffe-Campanacci syndrome and NF1. It was pointed out early on that some cases of what is now called JCS develop typical skin pigmentations (CAL spots and freckling) (99), which are now defining features of NF1 (2). Later, patients were diagnosed with metaphyseal bone lesions (defects/NOF) who also had developed neurofibromas (104) and fulfilled the current diagnostic criteria of NF1 $(40,106)$. The clinical diagnosis of the skeletal findings as lesions associated with NF1 requires the exclusion of endocrine disorders $(52,46,47,112)$. Meanwhile, the simultaneous 
occurrence of CGCG of the jaw and NOF of the long bones in cases with NF1 has been described in detail [40, 53 (in the latter case, jaw lesion was initially diagnosed as GCT)]. Recent genetic studies have shown that some patients with symptoms of JCS have constitutive NF1 gene mutations (67). In one JCS case, LOH of NF1 gene was identified in NOFs of long bones (113). Furthermore, somatic NF1 mutations were identified in cell cultures of jaw lesions originally diagnosed as CGCG - in two individuals who were diagnosed with JCS (67). However, the report does not provide data on long bone findings in these two individuals. From these findings and a detailed evaluation of the literature, it was convincingly demonstrated that NF1 can be diagnosed in most patients with pigmentation disorders of the skin and NOF or CGCG (67). However, the isolated occurrence of CGCG in an NF1 patient without long bone NOF (64) should not be called JCS, because the original definition of the syndrome excluded neurofibroma from the differential diagnosis (31), required the manifestation of long bone NOF and CAL spots (99), and referred to CGCG as an anecdotal finding (102). The frequent detection of constitutive NF1 mutations in most cases with JCS has established the conclusion that JCS is probably a manifestation of NF1 and not a distinct entity (67). So far, documentation of individual coincidences of CGCG, NOF, skin lesions and established diagnosis of NF1 is very limited (113-115). The case presented here supplements the rare reports on features related to JCS and NF1 providing further details on the genotype and phenotype of NF1.

Importance of CGCG in the diagnosis of JCS in NF1. A review has indicated that JCS is an entity not clearly defined (67). It seems plausible to assume that in the cases with radiological evidence of metaphyseal bone defects and characteristic skin findings, the X-ray examinations were carried out first, and only in some cases unusual skin findings were registered afterwards (99).

The skin findings will primarily have required differential diagnosis of NF1 (31), or another syndrome (102), with a combination of bone and skin findings. The importance of CGCG for diagnosing JCS is not clear either. Confusion about the diagnostic value of the jaw findings (CGCG) for JCS could also be due to an early review, which, based on an incorrect evaluation of current publications on this topic at that time, led to the assumption that the proportion of CGCG arising in the jaws was around $62 \%$ among patients with JCS (104). Mirra's assessment of diagnosing JCS in a case with CGCG but without long bone NOF fits into the argument, the exclusion of characteristic osteolysis of the long bones in individual cases is not an exclusion criterion for the diagnosis of the syndrome (102).

Later reports on JCS generally do not list any more jaw findings, but the exclusion of neurofibromas or neurofibromatosis is still mandatory for the definition of the entity (100). Based on the unexplained diagnostic criteria of JCS, it was only logical to rely on the examination of the potential etiological connection between NF1 and JCS predominantly in cases that had developed histologically confirmed NOF of long bones only (67). However, most patients in this international study group had clinical stigmata already confirming a diagnosis of NF1 (total number of cases: n=23; neurofibroma: $n=14$ ). Stewart et al. (67) have studied patients suspected of being affected by NF1 who were investigated by genetic testing for NF1 germline mutations. The selection criterion for the individuals of the study was the evidence of skeletal findings derived from different database sources, which are to be verified when JCS is suspected. This study included patients of earlier publications with known NF1 and a few borderline cases of JCS and NF1 to test the diagnostic accuracy of identifying JCS phenotypes as variants of NF1. This is not a study of sporadic cases with an incidental diagnosis of NOF/CGCG and an investigation of a potential NF1 background of affected individuals.

Three cases with CGCG were examined (67). Significantly, the detection of a NF1 mutation was negative in only one of the three cases with CGCG. This case is the only patient of the whole series who had developed both CGCG and NOF. The clinical diagnostic criteria of NF1 and JCS were not met in this case (diagnostically inconclusive pigmentation disorders of skin). The other two cases with CGCG who were classified as non-classical JCS, obviously had no NOF of the long bones (at least no radiographs of long bones) and germline and somatic NF1 mutations (67). The two individuals had certain characteristics of the jaw lesion, well documented for NF1 (46, 47), and clinical findings allowing an NF1 diagnosis. The authors explicitly state that it cannot be concluded from the previous studies that no JCS can develop without evidence for NF1 (67). The frequency of NOF in NF1 cannot be derived from this study. However, NOF is obviously a frequent diagnosis in adolescence (73). With a frequency of up to $30 \%$ in children and adolescents in the normal population, NOF should be found in NF1 patients much more frequently than previously assumed (94). The study supports the estimation that the originally described diagnostic triad of findings (97) is exceptionally rare both in relation to NF1 and in sporadic cases. The only case in the series published by Stewart et al. (67) who had developed the diagnostic triad of skin pigmentation disorders ('nevi'), CGCG and NOF (JCS), had no NF1.

From this review of reports on JCS, CGCG and NF1 it can be concluded:

The frequency of CGCG and NOF in NF1 is unknown. The coincidence of CGCG and NOF has been described very rarely in individuals not affected by NF1 (67) and in NF1 $(40,113,115)$. Apparently, only years of collecting bone 
findings can provide a substantial number of individual cases that meet the required diagnostic pattern (100). This is the largest series on the syndrome published so far and the only one that, based on long-term follow-up examinations, claims that in these cases, NF1 has been safely ruled out (100).

The very few reports on the coincidence of findings following the first description of the diagnostic triad (91) argue for a sporadic association (67).

Synchronous development of the jaw and long bone findings and NF1 can be demonstrated in individual cases $(40,113,115)$. At present, the coincidence of diagnostic criteria is not obligatorily used to define the case of JCS in NF1 (67).

The often-arbitrary subsumption of certain bone and skin findings under the sign "JCS" is detrimental to the use of the term as a diagnostic aid. Most cases are combinations of findings as partial aspects of an inheritable syndrome.

Diagnosis of CGCG combined with obvious pigmentation disorders of the skin should prompt the examination for stigmata of a syndromic disease.

The case presented here is a rarity, the phenotype of which must be differentiated from other diseases.

Cherubism. Cherubism is a disease of the jaws characterized by extensive transformation, remodeling, and cyst-like bone expansion, which can lead to extensive cheek swelling (116, 117). Facial findings can become very noticeable and disfiguring. The bone lesions develop as early as in childhood and show maximum extension usually during the first two decades of life $(116,117)$. The patient's chubbycheek appearance can progress to a facial phenotype that is remotely like angles (cherubim) depicted on Renaissance paintings. The bone lesions can extend into the orbit and even further than the maxillary part of the cavity (118). Although rare cases of bone lesions rich in giant cells arising outside the jaw have been reported in individuals with cherubism, lesions in the metaphyseal regions are not included in these reports (119).

The bone disease was defined as an autosomal-dominant heritable entity and metaphorically termed cherubism (117). Cherubism is a non-neoplastic, usually self-limiting jaw disease, from which an involution is expected during the third decade of life (119). The histological findings of the osseous lesion in cases of cherubism correspond to those of CGCG (120). Indeed, the formal pathogenesis of the skeletal lesions in a cherubism phenotype is described as the development of multiple, potentially confluent CGCG of the jaws (25).

The pathogenic mutation is on the $S H 3 B P 2$ gene of chromosome 4p16.3 (121, 122). Several studies have determined the differentiation between sporadic CGCG and osteolysis of the jaw in cherubism by determining constitutional and sporadic SH3BP2 mutations (123-125).
Identification of $S H 3 B P 2$ mutation is a valid proof for the inheritable disease (119). In some cases, SH3BP2 mutations have also been detected in CGCG. Since cherubism tends to occur during childhood, residual skeletal lesions in adulthood can look like a sporadic CGCG. From the size and extent of the lesion it cannot be inferred immediately to indicate or exclude the disease. Because of the frequently spontaneous regression of the lesions, a wait-and-see attitude is advocated. However, surgical treatment of cherubism is unavoidable in certain cases (126).

There are distinct hereditary diseases that can develop a cherubism-like phenotype in individual cases, e.g. triple $\mathrm{X}$ syndrome (127), Noonan syndrome and the so-called Noonan-like/multiple giant cell lesion syndrome (128-137), Ramon syndrome (138-140), and NF1 (29, 40, 54, 141-144). In all cases of cherubism defined as an inherited trait and in such syndromic diseases in which individual cases have a cherubism-like phenotype, CGCG is the morphological correlate of the lesion. No definite distinction can be made between a focally limited CGCG of the jaw and a case of extensive, disfiguring cherubism exclusively based on the microscopic image. The distinction between sporadic CGCG and a case of cherubism can be difficult, for example if a $S H 3 B P 2$ mutation is detected in CGCG (exon 11) and the mutation is not detected in the germline DNA (123). However, in studies on sporadic CGCG - without a cherubism phenotype - no mutations of the $S H 3 B P 2$ gene were detected $(24,125)$. Phenocopies of cherubism without evidence of SH3BP2 mutation should be called cherubismlike only in a descriptive sense (119). Indeed, the clinical/radiological phenotypes of large or multilocular CGCGs (62) can show gradual shifting to a case of cherubism, especially if the multilobulated osseous jaw lesion has expanded bilaterally and symmetrically in relation to the median sagittal plane of the body (41). Symmetry of bone lesions is a characteristic but not obligatory finding in cherubism $(144,145)$. Indeed, the assumption of complete involution of the bone lesion in patients with cherubism was not confirmed by radiological follow-up in adult patients (144). Residuals of the bone lesions were relatively common in adults and may have developed asymmetrically (144), which in individual cases - and without knowing the course of the lesion - may lead to diagnostic problems (123-125). Therefore, histological evidence of CGCG in adulthood does not exclude the diagnosis of cherubism, even with small or only circumscribed lesions. This knowledge of the variable phenotype of cherubism and cherubism-like entities underscores the importance of identifying the monogenetic basis of cherubism in the differential diagnosis of multiple osteolytic lesions of the jaw with prominent giant cells. Likewise, the presentation of a phenotype of bilateral mandibular CGCG that is almost identical over three generations does not provide evidence of an independent 
syndrome if a genetic test to rule out known syndromes is not carried out (146).

The exclusion of $S H 3 B P 2$ mutations in the present case excludes cherubism as the cause of the facial phenotype.

Cherubism and NF1. The few reports of NF1 patients with a cherubism-like phenotype and those of some with solitary or multiple CGCG of the jaws support the concept that both findings are phenotypic variants within the spectrum of NF1associated jaw lesions characterized by prominent giant cells. To our knowledge, there is no published case providing evidence of both SH3BP2 and NF1 mutations in an individual. Synchronous examinations of the skull and the entire skeleton in cases of NF1-associated cherubism are rare. However, there is at least one report that has ruled out limb lesions in a very extensive form of cherubism in an NF1 patient (143).

A striking finding in the present case is the complete emergence of the permanent teeth and the alignment of the teeth in a closed row of teeth (except for a few wisdom teeth). On the other hand, in cases of cherubism and the expansion of lesions in the alveolar process, tooth retention and aplasia of teeth are very often recorded $(46,119)$. The case of Vannelli et al. (113) describes a unilateral NF1associated cherubism with localization in the ramus mandibulae. This region is the typical starting point of osteolysis in cherubism. Influence of the lesion is restricted to mandibular ramus. Dentition is not expected in a section of the jaw that usually no longer contains teeth in the adolescent. Subsequent findings on the potential for further expansion of the lesion are not reported. In contrast, Martinez-Tello et al. (115) described a case of cherubism in NF1, in which the jaw lesions had a significant influence on the eruption and position of molars. From these reports on the cherubism phenotype in NF1, no pattern of the influence of the syndrome-associated lesions on the dentition can be derived. However, in many patients with unilateral plexiform neurofibromas of the second or third branch of the trigeminal nerve, the patient's (unilateral) dental findings are noticeably different from the anomalies of the tooth position and the number of teeth of the permanent dentition recorded in cases of NF1-associated cherubism.

In a current study, genotype-phenotype correlations for defined NF1 missense mutations were analyzed in 162 individuals with NF1 (147). The proportion of pulmonary stenosis was relatively low [2/113 (1.77\%)], the proportion of patients with a Noonan syndrome-phenotype was $7.5 \%$ (10/134). Overall, the proportion of adult patients with a severe phenotype was very high $(75 \%)$. The inclusion criteria defining a severe phenotype in this study had to present at least one of the following features in an individual: plexiform and/or symptomatic spinal neurofibromas, symptomatic optic pathway glioma, malignant neoplasm, or osseous lesions. Many of the patients in the study group were $>19$ years old (56/75 individuals). The term 'osseous lesion' included many entities. However, among the individuals with a diagnosis of 'osseous lesion' (48/144, $33.3 \%$ ), only 2 cases had no further specified bone cysts. The diagnosis 'cherubism' is listed as an inclusion criterion of skeletal lesions but is not mentioned as a definite finding in the presentation of results (147). Both cherubism and findings diagnostic for 'JCS' are probably very rarely related to NF1 missense mutations, at least in adult patients. On the other hand, NF1 patients with a large NF1 deletion developed bone cysts in about $50 \%$ of cases (148). Children and adolescents were also examined in this study. However, this publication took no account of jaw lesions or topography of the cysts and did not apply diagnostic criteria of JCS to the cohort (148).

The average age of the patient with cherubism is less than 10 years (149). A recently presented overview of reports on extensive and bilateral CGCG in $10 \mathrm{NF} 1$ patients shows that the average age of the patients is 30.2 years (41). Only one patient was younger than 10 years at the time of diagnosis of the jaw lesions and two were aged 11 years (41). It was emphasized that these patients had not developed a typical cherubism phenotype. However, extensive jaw lesions and multilocular formation have been described, including cases with lesions in both jaws (41). There appears to be a distinction between the early onset of jaw lesions in cherubism (usually noticeably below 10 years of age) and the (extensive) CGCG associated with NF1 (usually older than 10 years) concerning the age of diagnosis. Age of onset of CGCG in the presented report complies with data of syndromic cherubism-like jaw lesions.

The features of the presented case concerning the findings essential for JCS and a cherubism-like phenotype in NF1 are like those of the cases presented by Vannelli et al. (113) and Martinez-Tello et al. (115).

Alagille syndrome. The genetic disorder Alagille Syndrome (ALGS), also known as Alagille-Watson syndrome or arterio-hepatic dysplasia, is characterized by the combination of chronic bile drainage disorders (cholestasis) becoming symptomatic with congenital jaundice, dysmorphic findings of the face and eyes (embryotoxon; drusen of the optic nerve), diseases of the heart and malformation of proximal vessels (in particular: pulmonary artery stenosis), as well as anomalies of the vertebral arches (150). It is one of the most common causes of intrahepatic bile congestion in childhood (151). The anomaly of the bile ducts is diagnosed in about $90 \%$ of the cases (range: rarefaction of the biliary tract to complete biliary atresia). Abnormalities of the face are a pronounced forehead (balcony forehead, frontal bossing) associated with deep-set and widely spaced eyes (hypertelorism), a saddle nose, and a shortened chin region (152). The findings are different in number and form but add 
up to a characteristic of over $90 \%$ in this patient group (152154). The facial dysmorphism can turn out very subtle and escape observation (152-154). However, the evaluation criteria for facial dysmorphism were not published in every original paper (143-145). A high level of professional competence seems to be necessary to recognize the facial dysmorphism of the ALGS patient (155).

A further study on the diagnostic contribution of facial characteristics of ALGS patients has shown that these criteria can vary depending on the patient's ethnicity and must therefore be used in a relative way (155). Oral findings are rarely considered in ALGS and are non-specific, while the report of discolored teeth in an ALGS case is likely to be coincident $(156,157)$. So-called butterfly vertebral arches are frequent findings (158). The rate of bone fractures in patients is high (up to $21 \%)(141,144)$. Itching is a feature of ALGS (150).

ALGS is a very rare, autosomal dominant inheritable disease. The incidence of the disease is estimated at 1:30,000 to 1:50,000 live births (151). So far, two sub-types have been described. A mutation in the JAGl gene (location: chromosome 20p12.2) causes ALGS1. A mutation of the NOTCH2 gene (location: chromosome 1p13-p11) causes ALGS2. There are no genotype-phenotype correlations in ALGS (150, 158-160). Several findings of the patient apply to ALGS: itching, congenital hepatobiliary disorders, peripheral pulmonary artery stenosis, pale coloring of skin and facial hair, freckles, frontal bossing, and deep-set eyes. Pulmonary hypertension and itching are features of both ALGS (150) and NF1 [rare prevalence in large cohorts (160) and more frequent in genetically defined NF1 subgroups (161), especially in NF1 with Noonan-syndrome (162)]. Prominent frontal bone bossing was noticed in numerous syndromes, including NF1 patients with large deletions (143) and patients with Noonan syndrome $(162,163)$. Facial dysmorphism was attributed to the spectrum of NF1 (143, 147). However, the definition of facial dysmorphism usually remains vague (2) or is used as an undefined category in the evaluation $(164,165)$. Nevertheless, NF1 patients with large deletions tend to have a prominent forehead and eye positions somewhat more separated from each other in transversal plane (148). However, deep-set hyperteloric eyes are a feature of ALGS, too (150). Experimental studies suggest an impact of Jaggedl on midfacial development (166). The triangular shaped face is a feature of ALGS not present in the present case. However, the facial skeletal deformity due to the extensive CGCG can dissolve a skeletal contour characteristic in patients with ALGS. Indeed, the patient's chin region is quite prominent. The presented case is a mild form of ALGS. The identified JAGl mutation has not been reported. The mutation is rated a germline mutation and could be diagnostic ('likely pathogenic') for the patient's ALGS.
Craniofacial findings in patients with a history of fetal exposure to alcohol intoxication. Evidence shows that the patient is the child of a mother suffering from alcoholism. As noted, the newborn was dystrophic and small for her gestational age. Consequences of prenatal alcohol exposure for the organism are summarized under the term Fetal Alcohol Syndrome (167) or Fetal Alcohol Spectrum Disorders (FASD) (168). It is believed, that the multiple changes in the affected organism also have a genetic cause, as the alcohol intake during pregnancy affects the regulation of different genes during embryogenesis and in the fetal period (168). The features of FASD also include craniofacial changes, which must be considered in connection with the present patient's skeletal phenotype. However, the craniofacial manifestations of FASD are non-specific (169) and there is a great variation in the clinical features of FASD (167). A common FASD finding is a sagittally shortened nose with upturning the nose tip, occasionally associated with a short distance between the nose and lip $(170,171)$. A study on three-dimensional photographs of FASD children revealed that the morphological differences corresponded to the impression of general midface depression (170). Furthermore, significant differences were identified concerning the distance between the right and left sulcus nasi at the transition point to the philtrum (172). The soft tissue analyzes must be assessed in connection with cephalometric findings. In one study, frontal bossing, the lengthening of the mandibular body and deep nasolabial folds were diagnosed in fifteen American black children, which in the sum of findings generate the impression of midfacial hypoplasia. However, in the cases examined, neither the position nor the size of the midface deviated from the expected norm values, as determined on cephalograms (172). In contrast, another study in 90 children with a medical history of a FASD showed maxillary underdevelopment in horizontal and vertical direction. The vertical dimension of the mandibular ramus was shortened in relation to the total length of the face. The gonial angle was enlarged and the FASD patients developed a long face compared to age, sex and social class matched controls (173).

When comparing known FASD-associated craniofacial changes with the patient's facial findings, frontal bossing is shared between NF1 and ALGS phenotypes, while the midfacial hypoplasia and upturning nose pit may be a manifestation of FASD and ALGS. A comparison with the facial phenotype of the birth parents is not possible because there is no contact with them. There is an increased risk of fractures for children with FASD up to about eight years of age (174). The patient's pelvic fracture occurred a few years later than the calculated risk age (173). However, NF1-associated bone regeneration disorder can be another factor why a bone fracture occurred from a fall from relatively low height. Further pathogenic effects of the mother's alcoholic intake on the child 
Table II. Compilation of characteristic findings of the patient and various syndromes.

\begin{tabular}{|c|c|c|c|c|c|c|}
\hline Finding diagnostic for/associated with a disease & Patient & NF1 & $\mathrm{JCS}$ & Cherubism & ALGS & FASD \\
\hline Short stature and low body weight & + & + & - & - & + & + \\
\hline CAL spots & + & + & + & - & - & - \\
\hline Inguinal and axillary freckling & + & + & + & - & - & - \\
\hline Neurofibroma, multiple cutaneous & + & + & -1 & - & - & - \\
\hline Neurofibroma, diffuse & + & + & -1 & - & - & - \\
\hline NF1 germline mutation & + & + & -1 & - & - & - \\
\hline Giant cell granuloma of jaw ${ }^{2}$ & + & + & + & + & - & - \\
\hline Facial dysmorphology (not further specified) & + & $t^{3}$ & - & +3 & + & + \\
\hline Facial asymmetry & + & +4 & - & $(+)$ & - & - \\
\hline Frontal bossing & + & + & - & - & + & + \\
\hline Deep-set eyes (bilateral) ${ }^{5}$ & + & - & - & - & + & $(+)$ \\
\hline Saddle nose & + & $(+)^{5}$ & - & -6 & + & \\
\hline Upturning nose tip & + & - & - & - & + & + \\
\hline Small philtrum and lips, hardly any projection of the lips & + & - & - & - & + & + \\
\hline Metaphyseal defects/NOF of long bones & + & + & + & - & - & - \\
\hline Bone fracture (extragnathic) $)^{7}$ & + & + & $(+)$ & - & + & $(+)$ \\
\hline Elevated liver enzymes & + & - & - & - & + & $(+)$ \\
\hline Mental retardation & + & $(+)^{8}$ & $(+)^{8}$ & - & $(+)$ & $(+)$ \\
\hline Cardiovascular malformation & + & +9 & + & - & + & $(+)$ \\
\hline Itching & + & + & - & - & + & - \\
\hline
\end{tabular}

+: Evidence of finding; -: No evidence of finding/no data; (+): Finding associated with subgroups of the disease or recorded in individual cases. ${ }^{1}$ Stewart et al. (67) provide evidence for NF1 in most cases with JCS. ${ }^{2}$ Characteristically, but not obligatory bilaterally symmetrical/confluent lesions in cherubism and one-sided in NF1; not specified in JCS. However, bilateral and multifocal manifestations of CGCG have been described for both NF1 (113) and JCS (102). ${ }^{3}$ Beyond adolescence, facial dysmorphism can reduce to such an extent that a normal facial appearance is established (cherubism). An externally visible dysmorphism by CGCG is not mandatory (NF1, cherubism and JCS). Facial asymmetry in NF1 is more likely due to facial PNF than CGCG. ${ }^{4}$ Facial asymmetries in NF1 were observed in $28 \%$ of cases with type 1 large deletions (148). On the contrary, this finding was registered in only $8 \%$ of a general NF1 population (170). ${ }^{5} \mathrm{~A}$ wider nose has been described for subgroups of NF1 patients, e.g. large deletions of NF1 gene (148). ${ }^{6}$ In principle, expansion of the nasal skeleton is possible with cherubism. ${ }^{7}$ The assessment of bone fractures includes either the entire skeleton (NF1, ALGS, FASD) or only the extremity bones (JCS). NF1: frequently associated with vitamin D-deficiency. FASD: One study shows an increased fracture risk for the patient group up to the age of 8 years (174). ${ }^{8}$ Clinical studies on NF1 patients have revealed learning disabilities in a substantial number of patients (181). In review articles on JCS, mental retardation is a feature of some patients (100, 102). ${ }^{9}$ Cardiovascular malformations in some NF1 patients show geno- pheno-type relations (179). NF1: Neurofibromatosis type 1; JCS: Jaffe-Campanacci syndrome; ALGS: Alagille syndrome: FASD: Fetal alcohol syndrome disorder(s); CAL: Café-au-lait spots.

during embryonal stages cannot be excluded in the patient. However, the alcohol-toxic effects on the embryo's developing hepatobiliary and pulmonary system are individually variable and cannot be assigned to a certain phenotype (175).

Sex hormone receptors in CGCG. The report of estrogen receptor expression in NOF has opened the discussion that the typically self-limiting growth of the lesions during puberty, which are now classified as neoplasms, is controlled by sex hormones (76). The similarity of the morphology of NOF and CGCG suggests a similar expression pattern of the tumor cells. However, spontaneous regressions of the lesions are much less likely with NOF than CGCG (76). No estrogen receptor was detected in CGCG of the jaws (176). On the other hand, the results on the sex hormone receptor status of peripheral GCG of the jaws are inconsistent $(177,178)$. In the presented case, jawbone lesions were negative for estrogen receptor expression. Two further NF1-associated CGCG cases of jaws (female, age $<20$ years) were also estrogen receptor negative (unpublished results). It seems reasonable to speculate that the frequently different course of the two osseous lesions is at least partially regulated by the expression of sexual hormone receptors. Regression of the CGCG is typical only for cherubism (in the post-pubertal period) (119), largely unexplored for syndromic cherubism-like lesions and not to be expected in sporadic lesions $(46,47)$.

\section{Conclusion}

The coincidence of various diseases requires careful examination of individual findings to determine their potential pathological significance. In the individual phenotype, very different (epi)genetic factors can converge to a finding or association of various findings, e.g. in the craniofacial region (Table II). The genetic examination contributes significantly to diagnosis in individual cases (179). Careful clinical description of cases is the prerequisite of genetic studies $(67,100,180,181)$. Histological evaluation 
of skeletal lesions requires precise knowledge of radiological and clinical findings. The derivation of a characteristic facial expression from certain genetic traits and their relation to a syndrome seems problematic - at least in NF1 - considering the still very superficial general knowledge of genetic and epigenetic factors contributing to the facial appearance.

JCS is a poorly defined entity. Recent genetic results on NOF and CGCG suggest that there are sporadic and syndromeassociated bone lesions. The association of the characteristic bone and jaw lesions in NF1 patients has been proven, however the coincidence of both skeletal lesions has also been registered in other syndromic diseases with skin differentiation disorders (182). The assignment of the findings to a poorly defined syndrome does not result in any diagnostic value, thus this term should not be used as a diagnostic feature. Surgical treatment of the patient with cherubism-like phenotype must consider individual findings and in rare cases other diseases, be measured according to the individual needs of the patient and prevent foreseeable complications.

\section{Conflicts of Interest}

The Authors declare that there are no conflicts of interest regarding the publication presented.

\section{Authors' Contributions}

Design of study, writing the manuscript: REF, FKK, CH, IW, MZ; Treatment of patient: REF, TR; Histology: CH, JZ, AML; Genetics: IW, MZ; Correction of manuscript. All Authors.

\section{Acknowledgements}

Written and informed consent was obtained from the patient and her nursing mother to publish this case report. The Authors would like to thank the patient and mother for their cooperation in answering numerous questions about the patient's medical history. The authors appreciate the histological diagnoses of the long bone specimen provided by M. Brockmann, MD, Ph.D., pathologist, Cologne, H. Bürger, MD, Ph.D., pathologist, Paderborn, and M. Werner, MD, Ph.D., pathologist, Berlin. The Authors thank M. Yan, DMD, Hamburg, for the translation of scientific information that has been published in Chinese.

\section{References}

1 Ly KI and Blakeley JO: The diagnosis and management of neurofibromatosis type 1. Med Clin North Am 103(6): 10351054, 2019. PMID: 31582003. DOI: 10.1016/j.mena. 2019.07.004

2 Riccardi VM: Neurofibromatosis, phenotype, natural history, and pathogenesis. $2^{\text {nd }}$ Edition. The Johns Hopkins University Press, Baltimore, pp. 157-158, 1992.

3 Viskochil D, Buchberg AM, Xu G, Cawthon RM, Stevens J, Wolff RK, Culver M, Carey JC, Copeland NG and Jenkins NA: Deletions and a translocation interrupt a cloned gene at the neurofibromatosis type 1 locus. Cell 62(1): 187-192, 1990. PMID: 1694727. DOI: 10.1016/0092-8674(90)90252-a

4 Wallace MR, Marchuk DA, Andersen LB, Letcher R, Odeh HM, Saulino AM, Fountain JW, Brereton A, Nicholson J and Mitchell AL: Type 1 neurofibromatosis gene: Identification of a large transcript disrupted in three NF1 patients. Science 249(4965): 181-186, 1990. PMID: 2134734. DOI: 10.1126/ science. 2134734

5 Legius E, Marchuk DA, Collins FS and Glover TW: Somatic deletion of the neurofibromatosis type 1 gene in a neurofibrosarcoma supports a tumour suppressor gene hypothesis. Nat Genet 3(2): 122-126, 1993. PMID: 8499945. DOI: $10.1038 / \mathrm{ng} 0293-122$

6 Kluwe L, Friedrich R and Mautner VF: Loss of NF1 allele in schwann cells but not in fibroblasts derived from an NF1associated neurofibroma. Genes Chromosomes Cancer 24(3): 283-285, 1999. PMID: 10451710. DOI: 10.1002/(sici)10982264(199903)24:3<283::aid-gcc15>3.0.co;2-k

7 Laycock-van Spyk S, Thomas N, Cooper DN and Upadhyaya M: Neurofibromatosis type 1-associated tumours: Their somatic mutational spectrum and pathogenesis. Hum Genomics 5(6): 623-690, 2011. PMID: 22155606. DOI: 10.1186/1479-7364-56-623

8 Schindeler A and Little DG: Recent insights into bone development, homeostasis, and repair in type 1 neurofibromatosis (NF1). Bone 42(4): 616-622, 2008. PMID: 18248783. DOI: $10.1016 /$ j.bone.2007.11.006

9 Elefteriou F, Kolanczyk M, Schindeler A, Viskochil DH, Hock JM, Schorry EK, Crawford AH, Friedman JM, Little D, Peltonen J, Carey JC, Feldman D, Yu X, Armstrong L, Birch P, Kendler DL, Mundlos S, Yang FC, Agiostratidou G, HunterSchaedle K and Stevenson DA: Skeletal abnormalities in neurofibromatosis type 1: Approaches to therapeutic options. Am J Med Genet A 149A(10): 2327-2338, 2009. PMID: 19764036. DOI: 10.1002/ajmg.a.33045

10 Friedrich RE, Stelljes C, Hagel C, Giese M and Scheuer HA: Dysplasia of the orbit and adjacent bone associated with plexiform neurofibroma and ocular disease in $42 \mathrm{NF}-1$ patients. Anticancer Res 30(5): 1751-1764, 2010. PMID: 20592374.

11 Friedrich RE, Rother J, Christ G, Lehmann M, Eulenburg CG, Giese M and Scheuer HA: Analysis of orbital plain radiographs for orbital deformities in neurofibromatosis type 1 patients, with special reference to alterations of the orbital rim as indicators of adjacent plexiform neurofibroma. Anticancer Res 33(3): 1081-1090, 2013. PMID: 23482785.

12 Friedrich RE and Scheuer HT: Non-odontogenic intraosseous radiolucent lesions of the mandibular body are rare findings on panoramic views of patients with neurofibromatosis type 1 . Anticancer Res 39(4): 1971-1985, 2019. PMID: 30952741. DOI: 10.21873 /anticanres.13308

13 Happle R: Mosaic manifestation of autosomal dominant skin disorders. In: Mosaicism in human skin. R. Happle (ed.). Springer, Berlin, pp. 131, 2014.

14 Cohen MM Jr: Perspectives on craniofacial asymmetry. VI. The hamartoses. Int J Oral Maxillofac Surg 24(3): 195-200, 1995. PMID: 7594750. DOI: 10.1016/s0901-5027(06)80126-8

15 Köhler B: Neurofibromatose im Kindesalter. Wissenschaftliche Verlagsgesellschaft, Stuttgart, pp. 62-63, 1990.

16 Mulliken JB: Plastic surgery in neurofibromatosis. In: Neurofibromatosis. a handbook for patients, families, and 
health-care professionals. Rubinstein AE, Korf B (eds.). Thieme, New York, pp. 122, 1990.

17 Stevenson DA, Zhou H, Ashrafi S, Messiaen LM, Carey JC, D'Astous JL, Santora SD and Viskochil DH: Double inactivation of NF1 in tibial pseudarthrosis. Am J Hum Genet 79(1): 143-148, 2006. PMID: 16773574. DOI: 10.1086/504441

18 Stevenson DA, Yan J, He Y, Li H, Liu Y, Zhang Q, Jing Y, Guo Z, Zhang W, Yang D, Wu X, Hanson H, Li X, Staser K, Viskochil DH, Carey JC, Chen S, Miller L, Roberson K, Moyer-Mileur L, Yu M, Schwarz EL, Pasquali M and Yang FC: Multiple increased osteoclast functions in individuals with neurofibromatosis type 1 . Am J Med Genet A 155A(5): 1050-1059, 2011. PMID: 21465658. DOI: 10.1002/ajmg.a. 33965

19 Iqbal A, Tamgadge S, Tamgadge A and Chande M: Intraosseous neurofibroma in a 13-year-old male patient: A case report with review of literature. J Cancer Res Ther 14(3): 712-715, 2018. PMID: 29893349. DOI: 10.4103/0973-1482.176173

20 Che Z, Nam W, Park WS, Kim HJ, Cha IH, Kim HS, Yook JI, Kim J and Lee SH: Intraosseous nerve sheath tumors in the jaws. Yonsei Med J 47(2): 264-270, 2006. PMID: 16642559. DOI: $10.3349 / y m j .2006 .47 .2 .264$

21 Kurihara J, Yokoo S, Ichikawa M, Shimizu T, Ogawa M and Seki M: Intraosseous intraneural perineurioma derived from the inferior alveolar nerve with an abnormality of chromosome 22 and expression of the BCR-ABL fusion gene: Report of a case and review of recent literature. World J Surg Oncol 16(1): 189, 2018. PMID: 30213264. DOI: 10.1186/s12957-018-1481-8

22 Terry DG, Sauser DD and Gordon MD: Intraosseous malignant peripheral nerve sheath tumor in a patient with neurofibromatosis. Skeletal Radiol 27(6): 346-349, 1998. PMID: 9677654. DOI: 10.1007/s002560050395

23 Carinci F, Piattelli A, Martinelli M, Palmieri A, Rubini C, Fioroni M, Scapoli L, Laino G, Caputi S, Becchetti A and Pezzetti F: Genetic profiling of central giant cell granuloma of the jaws. J Craniofac Surg 16(3): 399-407, 2005. PMID: 15915104. DOI: 10.1097/01.scs.0000171965.39734.e8

24 Vered M, Buchner A and Dayan D: Central giant cell granuloma of the jawbones-new insights into molecular biology with clinical implications on treatment approaches. Histol Histopathol 23(9): 1151-1160, 2008. PMID: 18581286. DOI: $10.14670 / \mathrm{HH}-23.1151$

25 Freyschmidt J, Ostertag H and Jundt G (eds): Knochentumoren (mit Kiefertumoren). Springer, Berlin - Heidelberg, pp. 741755, pp. 876-897, pp. 1027-1033, 2010.

26 Jundt G: Central giant cell lesion. In: Pathology and genetics of head and neck tumours.Barnes L, Eveson H, Reichart P and Sidransky D (eds.). IARC Press, Lyon, pp. 236, 2005.

27 Chuong R, Kaban LB, Kozakewich H and Perez-Atayde A: Central giant cell lesions of the jaws: A clinicopathologic study. J Oral Maxillofac Surg 44(9): 708-713, 1986. PMID: 3462363. DOI: $10.1016 / 0278-2391(86) 90040-6$

28 Chrcanovic BR, Gomes CC, Dos Santos TR, Abreu MHNG and Gomez RS: Clinical factors associated with the recurrence of central giant cell lesions. J Oral Pathol Med 48(9): 799-802, 2019. PMID: 31353534. DOI: 10.1111/jop.12937

29 De Lange J and Van den Akker HP: Clinical and radiological features of central giant-cell lesions of the jaw. Oral Surg Oral Med Oral Pathol Oral Radiol Endod 99(4): 464-470, 2005. PMID: 15772595. DOI: 10.1016/j.tripleo.2004.11.015
30 Gupta S, Narwal A, Kamboj M, Devi A and Hooda A: Giant cell granulomas of jaws: A clinicopathologic study. J Oral Maxillofac Res 10(2): e5, 2019. PMID: 31404210. DOI: 10.5037/jomr.2019.10205

31 Jaffe HL: Giant-cell reparative granuloma, traumatic bone cyst, and fibrous (fibro-oseous) dysplasia of the jawbones. Oral Surg Oral Med Oral Pathol 6(1): 159-175, 1953. PMID: 13026160. DOI: 10.1016/0030-4220(53)90151-0

32 Werner M: Giant cell tumour of bone: Morphological, biological and histogenetical aspects. Int Orthop 30(6): 484-489, 2006. PMID: 17013643. DOI: 10.1007/s00264-006-0215-7

33 Presneau N, Baumhoer D, Behjati S, Pillay N, Tarpey P, Campbell PJ, Jundt G, Hamoudi R, Wedge DC, Loo PV, Hassan $\mathrm{AB}$, Khatri B, Ye H, Tirabosco R, Amary MF and Flanagan AM: Diagnostic value of H3F3A mutations in giant cell tumour of bone compared to osteoclast-rich mimics. J Pathol Clin Res 1(2): 113-123, 2015. PMID: 27499898. DOI: 10.1002/ cjp2.13

34 Venneker S, Szuhai K, Hogendoorn PCW and Bovée JVMG: Mutation-driven epigenetic alterations as a defining hallmark of central cartilaginous tumours, giant cell tumour of bone and chondroblastoma. Virchows Arch 476(1): 135-146, 2020. PMID: 31728625. DOI: 10.1007/s00428-019-02699-2

35 Abrams B and Shear M: A histological comparison of the giant cells in the central giant cell granuloma of the jaws and the giant cell tumor of long bone. J Oral Pathol 3(5): 217-223, 1974. PMID: 4218867. DOI: 10.1111/j.1600-0714.1974. tb01714.x

36 Hirschl S and Katz A: Giant cell reparative granuloma outside the jaw bone. Diagnostic criteria and review of the literature with the first case described in the temporal bone. Hum Pathol 5(2): 171-181, 1974. PMID: 4590573. DOI: 10.1016/s00468177(74)80064-x

37 Picci P, Baldini N, Sudanese A, Boriani S and Campanacci M: Giant cell reparative granuloma and other giant cell lesions of the bones of the hands and feet. Skeletal Radiol 15(6): 415-421, 1986. PMID: 3764467. DOI: 10.1007/BF00355097

38 Behjati S, Tarpey PS, Presneau N, Scheipl S, Pillay N, Van Loo P, Wedge DC, Cooke SL, Gundem G, Davies H, Nik-Zainal S, Martin S, McLaren S, Goodie V, Robinson B, Butler A, Teague JW, Halai D, Khatri B, Myklebost O, Baumhoer D, Jundt G, Hamoudi R, Tirabosco R, Amary MF, Futreal PA, Stratton MR, Campbell PJ and Flanagan AM: Distinct H3F3A and H3F3B driver mutations define chondroblastoma and giant cell tumor of bone. Nat Genet 45(12): 1479-1482, 2013. PMID: 24162739. DOI: $10.1038 / \mathrm{ng} .2814$

39 Gomes CC, Diniz MG, Amaral FR, Antonini Guimarães BV and Gomez RS: The highly prevalent H3F3A mutation in giant cell tumours of bone is not shared by sporadic central giant cell lesion of the jaws. Oral Surg Oral Med Oral Pathol Oral Radiol 118(5): 583-585, 2014. PMID: 25442495. DOI: 10.1016/ j.oooo.2014.07.011

40 Ruggieri M, Pavone V, Polizzi A, Albanese S, Magro G, Merino $\mathrm{M}$ and Duray $\mathrm{PH}$ : Unusual form of recurrent giant cell granuloma of the mandible and lower extremities in a patient with neurofibromatosis type 1. Oral Surg Oral Med Oral Pathol Oral Radiol Endod 87(1): 67-72, 1999. PMID: 9927083. DOI: 10.1016/s1079-2104(99)70297-0

41 Tosios K, Delli K and Makris N: Multiple osteolytic lesions of the jaws in a patient with neurofibromatosis type I. A case 
report and focused literature review. Oral Surgery 12(2): 126132, 2019. DOI: 10.1111/ors.12389

42 Flanagan AM, Nui B, Tinkler SM, Horton MA, Williams DM and Chambers TJ: The multinucleate cells in giant cell granulomas of the jaw are osteoclasts. Cancer 62(6): 11391145, 1988. PMID: 2457425. DOI: 10.1002/10970142(19880915)62:6<1139::aid-cncr2820620617>3.0.co;2-8

43 Flanagan AM and Speight PM: Giant cell lesions of the craniofacial bones. Head Neck Pathol 8(4): 445-453, 2014. PMID: 25409853. DOI: 10.1007/s12105-014-0589-6

44 Dos Santos B, Koth VS, Figueiredo MA, Salum FG and Cherubini K: Brown tumor of the jaws as a manifestation of tertiary hyperparathyroidism: A literature review and case report. Spec Care Dentist 38(3): 163-171, 2018. PMID: 29603323. DOI: $10.1111 / \mathrm{scd} .12284$

45 Izgi E and Ogul H: Giant cell reparative granuloma of the mandible with an aggressive radiological appearance. Ann R Coll Surg Engl 102(3): e75-e76, 2020. PMID: 31850797. DOI: 10.1308/rcsann.2019.0174

46 Schafer WG, Hine MK and Levy BM: A textbook of oral pathology, 4th edition, Saunders, Philadelphia, pp. 146-149 (CGCG), pp. 659 (Metaphyseal bone lesion and CGCG in hyperparathyreoidism), 1983.

47 Batsakis JG: Tumors of the head and neck. Clinical and pathological considerations, $2^{\text {nd }}$ edition, Williams \& Wilkins, Baltimore, pp. 396-398, 1979.

48 Betts NJ, Stewart JC, Fonseca RJ and Scott RF: Multiple central giant cell lesions with a Noonan-like phenotype. Oral Surg Oral Med Oral Pathol 76(5): 601-607, 1993. PMID: 8247501. DOI: 10.1016/0030-4220(93)90069-g

49 Sinnott BP and Patel M: Giant cell lesion of the jaw as a presenting feature of Noonan syndrome. BMJ Case Rep 2018: 2018. PMID: 29848529. DOI: 10.1136/bcr-2017-224115

50 Neumann TE, Allanson J, Kavamura I, Kerr B, Neri G, Noonan J, Cordeddu V, Gibson K, Tzschach A, Krüger G, Hoeltzenbein M, Goecke TO, Kehl HG, Albrecht B, Luczak K, Sasiadek MM, Musante L, Laurie R, Peters H, Tartaglia M, Zenker M and Kalscheuer V: Multiple giant cell lesions in patients with Noonan syndrome and cardio-facio-cutaneous syndrome. Eur J Hum Genet 17(4): 420-425, 2009. PMID: 18854871. DOI: 10.1038/ejhg.2008.188

51 Federici S, Griffiths D, Siberchicot F, Chateil JF, Gilbert B and Lacombe D: Oculo-ectodermal syndrome: A new tumour predisposition syndrome. Clin Dysmorphol 13(2): 81-83, 2004 PMID: 15057122. DOI: 10.1097/00019605-200404000-00005

52 Mermer S, Kayhan G, Karacelebi $\mathrm{E}$ and Percin FE: Oculoectodermal syndrome: A new case with giant cell granulomas and non-ossifying fibromas. Genet Couns 27(1): 77-81, 2016. PMID: 27192894.

53 van Damme PA and Mooren RE: Differentiation of multiple giant cell lesions, Noonan-like syndrome, and (occult) hyperparathyroidism. Case report and review of the literature. Int J Oral Maxillofac Surg 23(1): 32-36, 1994. PMID: 8163857. DOI: $10.1016 / \mathrm{s} 0901-5027(05) 80323-6$

54 Giese M: Die Veränderungen der Kiefer und der Zahnstellung bei Neurofibromatose Typ 1 (Morbus Recklinghausen), Medical Dissertation, University of Hamburg, pp. 31-32, 1995.

55 Ardekian L, Manor R, Peled M and Laufer D: Bilateral central giant cell granulomas in a patient with neurofibromatosis: Report of a case and review of the literature. J Oral Maxillofac
Surg 57(7): 869-872, 1999. PMID: 10416639. DOI: 10.1016/ s0278-2391(99)90833-9

56 Sarmento DJS, Carvalho SHG, Araújo JCWP Filho, Carvalho MV and Silveira ÉJDD: Florid cemento-osseous dysplasia and peripheral giant cell granuloma in a patient with neurofibromatosis 1. An Bras Dermatol 92(2): 249-252, 2017. PMID: 28538890. DOI: 10.1590/abd1806-4841.20175277

57 Krammer U, Wimmer K, Wiesbauer P, Rasse M, Lang S, Müllner-Eidenböck A and Frisch H: Neurofibromatosis 1: A novel NF1 mutation in an 11-year-old girl with a giant cell granuloma. J Child Neurol 18(5): 371-373, 2003. PMID: 12822827. DOI: $10.1177 / 08830738030180051901$

58 Yazdizadeh M, Tapia JL, Baharvand M and Radfar L: A case of neurofibromatosis-Noonan syndrome with a central giant cell granuloma. Oral Surg Oral Med Oral Pathol Oral Radiol Endod 98(3): 316-320, 2004. PMID: 15356469. DOI: 10.1016/ S1079210404000654

59 Edwards PC, Fantasia JE, Saini T, Rosenberg TJ, Sachs SA and Ruggiero S: Clinically aggressive central giant cell granulomas in two patients with neurofibromatosis 1. Oral Surg Oral Med Oral Pathol Oral Radiol Endod 102(6): 765-772, 2006. PMID: 17138179. DOI: $10.1016 /$ j.tripleo.2005.10.038

60 Friedrich RE, Mautner VF and Scheuer HA: Loss of heterozygosity in tumor cells of a recurrent mandibular giant cell granuloma in neurofibromatosis type 1. Anticancer Res 27(4A): 2079-2083, 2007. PMID: 17649825.

61 Chrcanovic BR, Gomez RS and Freire-Maia B: Neurofibromatosis type 1 associated with bilateral central giant cell granuloma of the mandible. J Craniomaxillofac Surg 39(7): 538-543, 2011. PMID: 21071237. DOI: $10.1016 /$ j.jcms.2010.10.014

62 Zenker M: Clinical manifestations of mutations in RAS and related intracellular signal transduction factors. Curr Opin Pediatr 23(4): 443-451, 2011. PMID: 21750428. DOI: 10.1097/ MOP.0b013e32834881dd

63 Friedrich RE, Grob TJ, Hollants S, Zustin J, Spaepen M, Mautner VF, Luebke AM, Hagel C, Legius E and Brems H: Recurrent multilocular mandibular giant cell granuloma in neurofibromatosis type 1: Evidence for second hit mutation of NF1 gene in the jaw lesion and treatment with curettage and bone substitute materials. J Craniomaxillofac Surg 44(8): 1054-1060, 2016. PMID: 27316856. DOI: 10.1016/j.jcms. 2016.05.010

64 Ernst LM, Quinn PD and Alawi F: Novel oral findings in Schimmelpenning syndrome. Am J Med Genet A 143A(8): 881883, 2007. PMID: 17366580. DOI: 10.1002/ajmg.a.31663

65 Nguyen CT and Hofstede TM: Prosthodontic treatment and medical considerations for a patient with Turner syndrome: A clinical report. J Prosthodont 21(7): 552-555, 2012. PMID: 22672559. DOI: 10.1111/j.1532-849X.2012.00868.x

66 Miller DT, Freedenberg D, Schorry E, Ullrich NJ, Viskochil D, Korf BR, Council on Genetics and American college of medical genetics and genomics: Health supervision for children with neurofibromatosis type 1. Pediatrics 143(5): e20190660, 2019. PMID: 31010905. DOI: 10.1542/peds.2019-0660

67 Stewart DR, Brems H, Gomes AG, Ruppert SL, Callens T, Williams J, Claes K, Bober MB, Hachen R, Kaban LB, Li H, Lin A, McDonald M, Melancon S, Ortenberg J, Radtke HB, Samson I, Saul RA, Shen J, Siqveland E, Toler TL, van Maarle M, Wallace M, Williams M, Legius E and Messiaen L: JaffeCampanacci syndrome, revisited: Detailed clinical and 
molecular analyses determine whether patients have neurofibromatosis type 1 , coincidental manifestations, or a distinct disorder. Genet Med 16(6): 448-459, 2014. PMID: 24232412. DOI: $10.1038 /$ gim.2013.163

68 Reichart PA and Philipsen HP: Odontogenic tumors and allied lesions, Quintessence Books, London, pp. 319-332, 2004.

69 Gomes CC, Diniz MG, Bastos VC, Bernardes VF and Gomez RS: Making sense of giant cell lesions of the jaws (GCLJ): Lessons learned from next-generation sequencing. J Pathol 250(2): 126133, 2020. PMID: 31705763. DOI: 10.1002/path.5365

70 Nielsen GP and Kyriakos M: Fibrohistiocytic tumours. In: WHO classification of tumours of bone and soft tissue. Fletcher CDM, Bridge J, Hogendoorn PCW, Mertens F (eds.). IARC Press, Lyon, pp. 301-304, 2013.

71 Jaffe HL and Lichtenstein L: Non-osteogenic fibroma of bone. Am J Pathol 18(2): 205-221, 1942. PMID: 19970624

72 Andreacchio A, Alberghina F, Testa G and Canavese F: Surgical treatment for symptomatic non-ossifying fibromas of the lower extremity with calcium sulfate grafts in skeletally immature patients. Eur J Orthop Surg Traumatol 28(2): 291-297, 2018. PMID: 28819829. DOI: 10.1007/s00590-017-2028-3

73 Herget GW, Mauer D, Krauß T, El Tayeh A, Uhl M, Südkamp NP and Hauschild O: Non-ossifying fibroma: Natural history with an emphasis on a stage-related growth, fracture risk and the need for follow-up. BMC Musculoskelet Disord 17: 147, 2016. PMID: 27044378. DOI: 10.1186/s12891-016-1004-0

74 Mankin HJ, Trahan CA, Fondren G and Mankin CJ: Nonossifying fibroma, fibrous cortical defect and Jaffe-Campanacci syndrome: A biologic and clinical review. Chir Organi Mov 93(1): 1-7, 2009. PMID: 19711155. DOI: 10.1007/s12306-0090016-4

75 Baumhoer D, Kovac M, Sperveslage J, Ameline B, Strobl AC, Krause A, Trautmann M, Wardelmann E, Nathrath M, Höller S, Hardes J, Gosheger G, Krieg AH, Vieth V, Tirabosco R, Amary F, Flanagan AM and Hartmann W: Activating mutations in the MAPkinase pathway define non-ossifying fibroma of bone. J Pathol 248(1): 116-122, 2019. PMID: 30549028. DOI: 10.1002/path.5216

76 Bovée JV and Hogendoorn PC: Non-ossifying fibroma: A RASMAPK driven benign bone neoplasm. J Pathol 248(2): 127-130, 2019. PMID: 30809793. DOI: 10.1002/path.5259

77 Fauré C, Laurent JM, Schmit P and Sirinelli D: Multiple and large non-ossifying fibromas in children with neurofibromatosis. Ann Radiol (Paris) 29(3-4): 369-373, 1986. PMID: 3092720.

78 Erlemann R, Fischedick AR, Edel G, Peters PE and Galanski M: [Neurofibromatosis and multiple nonossifying bone fibromas]. Rofo 147(1): 20-24, 1987. PMID: 3039595. DOI: $10.1055 / \mathrm{s}-2008-1048583$

79 Gross ML, Soberman N, Dorfman HD and Seimon LP: Case report 556: Multiple non-ossifying fibromas of long bones in a patient with neurofibromatosis. Skeletal Radiol 18(5): 389-391, 1989. PMID: 2506648. DOI: 10.1007/BF00361432

80 Schaefer IM, Ströbel P, Thiha A, Sohns JM, Mühlfeld C, Küffer S, Felmerer G, Stepniewski A, Pauli S and Agaimy A: Soft tissue perineurioma and other unusual tumors in a patient with neurofibromatosis type 1. Int J Clin Exp Pathol 6(12): 30033008, 2013. PMID: 24294391.

81 Cherix S, Bildé Y, Becce F, Letovanec I and Rüdiger HA: Multiple non-ossifying fibromas as a cause of pathological femoral fracture in Jaffe-Campanacci syndrome. BMC
Musculoskelet Disord 15: 218, 2014. PMID: 24965055. DOI: 10.1186/1471-2474-15-218

82 Gill JR, El Nakhal TM, Park SM and Chomicki M: Pathological fracture of non-ossifying fibroma associated with neurofibromatosis type 1. BMJ Case Rep 12(7): e228170 , 2019. PMID: 31331926. DOI: 10.1136/bcr-2018-228170

83 Yesilda ̆ A, Baykal B, Ayata A, Kerman G, Koroglu M, Olgar $\mathrm{S}$ and Oyar O: Lhermitte-Duclos disease associated with neurofibromatosis type-1 and non-ossifying fibroma. Acta Radiol 46(1): 97-100, 2005. PMID: 15841746. DOI: 10.1080/ 02841850510020932

84 Su W, Shi X, Lin M, Huang C, Wang L, Song H, Zhuang Y, Zhang $\mathrm{H}$, Li $\mathrm{N}$ and $\mathrm{Li} \mathrm{X}$ : Non-ossifying fibroma with a pathologic fracture in a 12-year-old girl with tricho-rhinophalangeal syndrome: a case report. BMC Med Genet 19(1): 211, 2018. PMID: 30541476. DOI: 10.1186/s12881-018-0732-4

85 Leehey DJ, Ing TS and Daugirdas JT: Fanconi syndrome associated with a non-ossifying fibroma of bone. Am J Med 78(4): 708-710, 1985. PMID: 3985044. DOI: 10.1016/00029343(85)90419-x

86 Peacock JD, Dykema KJ, Toriello HV, Mooney MR, Scholten DJ 2nd, Winn ME, Borgman A, Duesbery NS, Hiemenga JA, Liu C, Campbell S, Nickoloff BP, Williams BO and Steensma M: Oculoectodermal syndrome is a mosaic RASopathy associated with KRAS alterations. Am J Med Genet A 167(7): 1429-1435, 2015. PMID: 25808193. DOI: 10.1002/ajmg.a.37048

87 Sane S, Yunis E and Greer R: Subperiosteal or cortical cyst and intramedullary neurofibromatosis - uncommon manifestations of neurofibromatosis. A case report. J Bone Joint Surg Am 53(6): 1194-1200, 1971. PMID: 4999155.

88 Lavell A, Jones CW, Wong D, Counsel P and Carey-Smith R: Plexiform neurofibroma causing an ossifying subperiosteal haematoma: A rare case in the tibia of an 11-year-old girl. Skeletal Radiol 46(10): 1405-1413, 2017. PMID: 28623408. DOI: $10.1007 / \mathrm{s} 00256-017-2689-3$

89 Lee HC and Cho DY: Assessment of sacrum scalloping in neurofibromatosis type 1 caused by a giant cell lesion of the sacrum. Surg Neurol 65(2): 194-8; discussion 198, 2006. PMID: 16427426. DOI: 10.1016/j.surneu.2005.05.023

90 Tsai LL, Drubach L, Fahey F, Irons M, Voss S and Ullrich NJ: [18F]-Fluorodeoxyglucose positron emission tomography in children with neurofibromatosis type 1 and plexiform neurofibromas: correlation with malignant transformation. J Neurooncol 108(3): 469-475, 2012. PMID: 22407214. DOI: 10.1007/s11060-012-0840-5

91 Hatori M, Hosaka M, Watanabe M, Moriya T, Sasano H and Kokubun S: Osteosarcoma in a patient with neurofibromatosis type 1: A case report and review of the literature. Tohoku J Exp Med 208(4): 343-348, 2006. PMID: 16565597. DOI: 10.1620/ tjem.208.343

92 Mandell GA, Dalinka MK and Coleman BG: Fibrous lesions in the lower extremities in neurofibromatosis. AJR Am J Roentgenol 133(6): 1135-1138, 1979. PMID: 116506. DOI: 10.2214/ajr.133.6.1135

93 Qutbi M, Ghanbari S, Asli IN and Shafiei B: Jaffe-Campanacci syndrome: Any role for $99 \mathrm{mTc}-m e t h y l e n e$ diphosphonate bone and $99 \mathrm{~m} \mathrm{Tc}$-octreotide scans for evaluation of the disorder? World J Nucl Med 18(2): 189-191, 2019. PMID: 31040754. DOI: 10.4103/wjnm.WJNM_21_18 
94 Jaremko JL, MacMahon PJ, Torriani M, Merker VL, Mautner VF, Plotkin SR and Bredella MA: Whole-body MRI in neurofibromatosis: Incidental findings and prevalence of scoliosis. Skeletal Radiol 41(8): 917-923, 2012. PMID: 22146869. DOI: $10.1007 / \mathrm{s} 00256-011-1333-\mathrm{x}$

95 Hegenscheid K, Kühn JP, Völzke H, Biffar R, Hosten N and Puls R: Whole-body magnetic resonance imaging of healthy volunteers: Pilot study results from the population-based SHIP study. Rofo 181(8): 748-759, 2009. PMID: 19598074. DOI: $10.1055 / \mathrm{s}-0028-1109510$

96 Ahlawat S, Blakeley JO, Langmead S, Belzberg AJ and Fayad LM: Current status and recommendations for imaging in neurofibromatosis type 1 , neurofibromatosis type 2 , and schwannomatosis. Skeletal Radiol 49(2): 199-219, 2020. PMID: 31396668. DOI: 10.1007/s00256-019-03290-1

97 Mirra JM, Gold RH and Rand F: Disseminated nonossifying fibromas in association with café-au-lait spots (JaffeCampanacci syndrome). Clin Orthop Relat Res (168): 192-205, 1982. PMID: 7105545.

98 Campanacci M, Laus M and Boriani S: Multiple non-ossifying fibromata with extraskeletal anomalies: a new syndrome? J Bone Joint Surg Br 65(5): 627-632, 1983. PMID: 6643569. DOI: $10.1302 / 0301-620 X .65 B 5.6643569$

99 Jaffe HL: Tumor and tumorous conditions of the bones and joints. Lea and Febiger, Philadelphia, pp. 242-254, 1958.

100 Campanacci M: Bone and soft tissue tumors. 2nd edition. Piccin Nuova Libraria, Padova \& Springer Verlag, Wien - New York, pp. 73-98, 1135-1143, 1999.

101 DeBella K, Szudek J and Friedman JM: Use of the national institutes of health criteria for diagnosis of neurofibromatosis 1 in children. Pediatrics 105(3 Pt 1): 608-614, 2000. PMID: 10699117. DOI: 10.1542 peds.105.3.608

102 Mirra J: Bone tumors. Clinical, radiologic and pathologic correlations. Lea and Febiger, Philadelphia, pp. 719-735, 828, 1989.

103 Jett $\mathrm{K}$ and Friedman JM: Clinical and genetic aspects of neurofibromatosis 1. Genet Med 12(1): 1-11, 2010. PMID: 20027112. DOI: 10.1097/GIM.0b013e3181bf15e3

104 Steinmetz JC, Pilon VA and Lee JK: Jaffe-Campanacci syndrome. J Pediatr Orthop 8(5): 602-604, 1988. PMID: 3139710. DOI: $10.1097 / 01241398-198809000-00021$

105 Hau MA, Fox EJ, Cates JM, Brigman BE and Mankin HJ: Jaffe-Campanacci syndrome. A case report and review of the literature. J Bone Joint Surg Am 84(4): 634-638, 2002. PMID: 11940628.

106 Colby RS and Saul RA: Is Jaffe-Campanacci syndrome just a manifestation of neurofibromatosis type 1 ? Am J Med Genet A 123A(1): 60-63, 2003. PMID: 14556247. DOI: 10.1002/ajmg.a. 20490

107 Al-Rikabi AC, Ramaswamy JC and Bhat VV: Jaffe-Campanacci syndrome. Saudi Med J 26(1): 104-106, 2005. PMID: 15756363.

108 Sonar M, Isik M, Ekmekci AY and Solmaz OA: Pathological fractures on both lower limbs with Jaffe-Campanacci's syndrome. BMJ Case Rep 2012: 2012. PMID: 23087282. DOI: 10.1136/bcr-2012-007047

109 Choi EM, Jung N, Shim YJ, Choi HJ, Kim JS, Kim HS, Song KS, Lee HJ and Kim SP: Short stature and growth hormone deficiency in a girl with encephalocraniocutaneous lipomatosis and Jaffe-Campanacci syndrome: A case report. Ann Pediatr
Endocrinol Metab 21(4): 240-244, 2016. PMID: 28164079. DOI: 10.6065/apem.2016.21.4.240

110 Campanacci M: Osteofibrous dysplasia of long bones a new clinical entity. Ital J Orthop Traumatol 2(2): 221-237, 1976. PMID: 1024109.

111 Campanacci M and Laus M: Osteofibrous dysplasia of the tibia and fibula. J Bone Joint Surg Am 63(3): 367-375, 1981. PMID: 7204433 .

112 Wong CL, Fok CK and Tam VH: Concurrent primary hyperparathyroidism and pheochromocytoma in a Chinese lady with neurofibromatosis type 1. Endocrinol Diabetes Metab Case Rep 2018, 2018. PMID: 29623209. DOI: 10.1530/EDM-18-0006

113 Vannelli S, Buganza R, Runfola F, Mussinatto I, Andreacchio A and de Sanctis L: Jaffe-Campanacci syndrome or neurofibromatosis type 1: A case report of phenotypic overlap with detection of NF1 gene mutation in non-ossifying fibroma. Ital J Pediatr 46(1): 2020. PMID: 32393377. DOI: 10.1186/s13052-0200813-9

114 Blau RA, Zwick DL and Westphal RA: Multiple non-ossifying fibromas. A case report. J Bone Joint Surg Am 70(2): 299-304, 1988. PMID: 3343278.

115 Martínez-Tello FJ, Manjón-Luengo P, Martin-Pérez M and Montes-Moreno S: Cherubism associated with neurofibromatosis type 1, and multiple osteolytic lesions of both femurs: A previously undescribed association of findings. Skeletal Radiol 34(12): 793-798, 2005. PMID: 16096755. DOI: 10.1007/s00256005-0938-3

116 Jones W: Familial multilocular cystic disease of the jaws. The American Journal of Cancer 17(4): 946-950, 2013. DOI: 10.1158/ajc. 1933.946

117 Jones WA, Gerrie $\mathrm{J}$ and Pritchard $\mathrm{J}$ : Cherubism-familial fibrous dysplasia of the jaws. J Bone Joint Surg Br 32-B(3): 334-347, 1950. PMID: 14778852. DOI: 10.1302/0301-620X. 32B3.334

118 Carroll AL and Sullivan TJ: Orbital involvement in cherubism. Clin Exp Ophthalmol 29(1): 38-40, 2001. PMID: 11272784. DOI: $10.1046 / j .1442-9071.2001 .00363 . x$

119 Papadaki ME, Lietman SA, Levine MA, Olsen BR, Kaban LB and Reichenberger EJ: Cherubism: Best clinical practice. Orphanet J Rare Dis 7 Suppl 1: S6, 2012. PMID: 22640403. DOI: $10.1186 / 1750-1172-7-S 1-S 6$

120 Yamaguchi T, Dorfman HD and Eisig S: Cherubism: Cinicopathologic features. Skeletal Radiol 28(6): 350-353, 1999. PMID: 10450884. DOI: 10.1007/s002560050530

121 Tiziani V, Reichenberger E, Buzzo CL, Niazi S, Fukai N, Stiller M, Peters H, Salzano FM, Raposo do Amaral CM and Olsen BR: The gene for cherubism maps to chromosome 4p16. Am J Hum Genet 65(1): 158-166, 1999. PMID: 10364528. DOI: $10.1086 / 302456$

122 Ueki Y, Tiziani V, Santanna C, Fukai N, Maulik C, Garfinkle J, Ninomiya C, doAmaral C, Peters H, Habal M, Rhee-Morris L, Doss JB, Kreiborg S, Olsen BR and Reichenberger E: Mutations in the gene encoding c-Abl-binding protein SH3BP2 cause cherubism. Nat Genet 28(2): 125-126, 2001. PMID: 11381256. DOI: $10.1038 / 88832$

123 Carvalho VM, Perdigão PF, Amaral FR, de Souza PE, De Marco L and Gomez RS: Novel mutations in the SH3BP2 gene associated with sporadic central giant cell lesions and cherubism. Oral Dis 15(1): 106-110, 2009. PMID: 19017279. DOI: $10.1111 / \mathrm{j} .1601-0825.2008 .01499 . x$ 
124 de Lange J, van Maarle MC, van den Akker HP and Redeker EJ: DNA analysis of the SH3BP2 gene in patients with aggressive central giant cell granuloma. Br J Oral Maxillofac Surg 45(6): 499-500, 2007. PMID: 16713042. DOI: 10.1016/ j.bjoms.2006.03.017

125 Idowu BD, Thomas G, Frow R, Diss TC and Flanagan AM: Mutations in SH3BP2, the cherubism gene, were not detected in central or peripheral giant cell tumours of the jaw. Br J Oral Maxillofac Surg 46(3): 229-230, 2008. PMID: 17544554. DOI: 10.1016/j.bjoms.2007.04.014

126 Friedrich RE, Scheuer HA, Zustin J and Grob T: Cherubism: A case report with surgical intervention. Anticancer Res 36(6): 3109-3115, 2016. PMID: 27272835.

127 Quan F, Grompe M, Jakobs P and Popovich BW: Spontaneous deletion in the FMR 1 gene in a patient with fragile $\mathrm{X}$ syndrome and cherubism. Hum Mol Genet 4(9): 1681-1684, 1995. PMID: 8541863. DOI: $10.1093 / \mathrm{hmg} / 4.9 .1681$

128 Dunlap C, Neville B, Vickers RA, O'Neil D and Barker B: The Noonan syndrome/cherubism association. Oral Surg Oral Med Oral Pathol 67(6): 698-705, 1989. PMID: 2740093. DOI: 10.1016/0030-4220(89)90012-1

129 Levine B, Skope L and Parker R: Cherubism in a patient with Noonan syndrome: Report of a case. J Oral Maxillofac Surg 49(9): 1014-1018, 1991. PMID: 1886012. DOI: 10.1016/02782391(91)90069-x

130 Betts NJ, Stewart JC, Fonseca RJ and Scott RF: Multiple central giant cell lesions with a Noonan-like phenotype. Oral Surg Oral Med Oral Pathol 76(5): 601-607, 1993. PMID: 8247501. DOI: 10.1016/0030-4220(93)90069-g

131 Addante RR and Breen GH: Cherubism in a patient with Noonan's syndrome. J Oral Maxillofac Surg 54(2): 210-213, 1996. PMID: 8604072. DOI: 10.1016/s0278-2391(96)90449-8

132 Wolvius EB, de Lange J, Smeets EE, van der Wal KG and van den Akker HP: Noonan-like/multiple giant cell lesion syndrome: Report of a case and review of the literature. J Oral Maxillofac Surg 64(8): 1289-1292, 2006. PMID: 16860226. DOI: $10.1016 /$ j.joms.2006.04.025

133 Tartaglia M, Mehler EL, Goldberg R, Zampino G, Brunner HG, Kremer H, van der Burgt I, Crosby AH, Ion A, Jeffery S, Kalidas K, Patton MA, Kucherlapati RS and Gelb BD: Mutations in PTPN11, encoding the protein tyrosine phosphatase SHP-2, cause Noonan syndrome. Nat Genet 29(4): 465-468, 2001. PMID: 11704759. DOI: $10.1038 / n g 772$

134 Jafarov T, Ferimazova N and Reichenberger E: Noonan-like syndrome mutations in PTPN11 in patients diagnosed with cherubism. Clin Genet 68(2): 190-191, 2005. PMID: 15996221. DOI: $10.1111 / \mathrm{j} .1399-0004.2005 .00475 . \mathrm{x}$

135 Lee JS, Tartaglia M, Gelb BD, Fridrich K, Sachs S, Stratakis CA, Muenke M, Robey PG, Collins MT and Slavotinek A: Phenotypic and genotypic characterisation of Noonanlike/multiple giant cell lesion syndrome. J Med Genet 42(2): e11, 2005. PMID: 15689434. DOI: 10.1136/jmg.2004. 024091

136 Beneteau C, Cavé H, Moncla A, Dorison N, Munnich A, Verloes A and Leheup B: SOS1 and PTPN11 mutations in five cases of Noonan syndrome with multiple giant cell lesions. Eur J Hum Genet 17(10): 1216-1221, 2009. PMID: 19352411. DOI: 10.1038/ejhg.2009.44

137 Hanna N, Parfait B, Talaat IM, Vidaud M and Elsedfy HH: SOS1: A new player in the Noonan-like/multiple giant cell lesion syndrome. Clin Genet 75(6): 568-571, 2009. PMID: 19438935. DOI: 10.1111/j.1399-0004.2009.01149.x

138 Pina-Neto JM, Moreno AF, Silva LR, Velludo MA, Petean EB, Ribeiro MV, Athayde-Junior L and Voltarelli JC: Cherubism, gingival fibromatosis, epilepsy, and mental deficiency (Ramon syndrome) with juvenile rheumatoid arthritis. Am J Med Genet 25(3): 433-441, 1986. PMID: 3789007. DOI: 10.1002/ajmg. 1320250305

139 Suhanya J, Aggarwal C, Mohideen K, Jayachandran S and Ponniah I: Cherubism combined with epilepsy, mental retardation and gingival fibromatosis (Ramon syndrome): A case report. Head Neck Pathol 4(2): 126-131, 2010. PMID: 20512637. DOI: $10.1007 / \mathrm{s} 12105-009-0155-9$

140 Surej Kumar LK, Deepa DS and Dilna S: Ramon syndrome- A rare form of Cherubism. Ann Maxillofac Surg 9(2): 415-418, 2019. PMID: 31909027. DOI: 10.4103/ams.ams_12_19

141 van Capelle CI, Hogeman PH, van der Sijs-Bos CJ, Heggelman BG, Idowu B, Slootweg PJ, Wittkampf AR and Flanagan AM: Neurofibromatosis presenting with a cherubism phenotype. Eur J Pediatr 166(9): 905-909, 2007. PMID: 17120035. DOI: 10.1007/s00431-006-0334-6

142 de Lange J, van den Akker HP and van den Berg H: Central giant cell granuloma of the jaw: A review of the literature with emphasis on therapy options. Oral Surg Oral Med Oral Pathol Oral Radiol Endod 104(5): 603-615, 2007. PMID: 17703964. DOI: $10.1016 /$ j.tripleo.2007.04.003

143 Hachach-Haram N, Gerarchi P, Benyon SL, Saggar A, McLellan G and Kirkpatrick WN: Multidisciplinary surgical management of cherubism complicated by neurofibromatosis type 1. J Craniofac Surg 22(6): 2318-2322, 2011. PMID: 22134267. DOI: $10.1097 /$ SCS.0b013e318232a779

144 Redfors M, Jensen JL, Storhaug K, Prescott T and Larheim TA: Cherubism: Panoramic and CT features in adults. Dentomaxillofac Radiol 42(10): 20130034, 2013. PMID: 24048692. DOI: $10.1259 / \mathrm{dmfr} .20130034$

145 Arnott DG: Cherubism - an initial unilateral presentation. Br J Oral Surg 16(1): 38-46, 1978. PMID: 280369. DOI: $10.1016 / \mathrm{s} 0007-117 \mathrm{x}(78) 80054-7$

146 Tecco S, Caruso S, Nota A, Leocata P, Cipollone G, Gatto R and Cutilli T: Bilateral central giant cell granuloma of the mandibular angle in three females from the same family. Head Face Med 14(1): 14, 2018. PMID: 30180903. DOI: 10.1186/ s13005-018-0171-7

147 Koczkowska M, Chen Y, Callens T, Gomes A, Sharp A, Johnson S, Hsiao MC, Chen Z, Balasubramanian M, Barnett CP, Becker TA, Ben-Shachar S, Bertola DR, Blakeley JO, Burkitt-Wright EMM, Callaway A, Crenshaw M, Cunha KS, Cunningham M, D'Agostino MD, Dahan K, De Luca A, Destrée A, Dhamija R, Eoli M, Evans DGR, Galvin-Parton P, George-Abraham JK, Gripp KW, Guevara-Campos J, Hanchard NA, Hernández-Chico C, Immken L, Janssens S, Jones KJ, Keena BA, Kochhar A, Liebelt J, Martir-Negron A, Mahoney MJ, Maystadt I, McDougall C, McEntagart M, Mendelsohn N, Miller DT, Mortier G, Morton J, Pappas J, Plotkin SR, Pond D, Rosenbaum K, Rubin K, Russell L, Rutledge LS, Saletti V, Schonberg R, Schreiber A, Seidel M, Siqveland E, Stockton DW, Trevisson E, Ullrich NJ, Upadhyaya M, van Minkelen R, Verhelst H, Wallace MR, Yap YS, Zackai E, Zonana J, Zurcher V, Claes K, Martin Y, Korf BR, Legius E and Messiaen LM: Genotype-phenotype correlation in NF1: Evidence for a more severe phenotype associated with missense mutations 
affecting NF1 codons 844-848. Am J Hum Genet 102(1): 69-87, 2018. PMID: 29290338. DOI: 10.1016/j.ajhg.2017.12.001

148 Mautner VF, Kluwe L, Friedrich RE, Roehl AC, Bammert S, Högel J, Spöri H, Cooper DN and Kehrer-Sawatzki H: Clinical characterisation of 29 neurofibromatosis type-1 patients with molecularly ascertained $1.4 \mathrm{Mb}$ type-1 NF1 deletions. J Med Genet 47(9): 623-630, 2010. PMID: 20543202. DOI: 10.1136/ jmg.2009.075937

149 Machado RA, Pontes H, Pires FR, Silveira HM, Bufalino A, Carlos R, Tuji FM, Alves D, Santos-Silva AR, Lopes MA, Capistrano HM, Coletta RD and Fonseca FP: Clinical and genetic analysis of patients with cherubism. Oral Dis 23(8): 1109-1115, 2017. PMID: 28644570. DOI: 10.1111/odi. 12705

150 Alagille D, Odièvre M, Gautier M and Dommergues JP: Hepatic ductular hypoplasia associated with characteristic facies, vertebral malformations, retarded physical, mental, and sexual development, and cardiac murmur. J Pediatr 86(1): 63-71, 1975. PMID: 803282. DOI: 10.1016/s0022-3476 (75) $80706-2$

151 Kamath BM, Baker A, Houwen R, Todorova L and Kerkar N: Systematic review: The epidemiology, natural history, and burden of Alagille syndrome. J Pediatr Gastroenterol Nutr 67(2): 148-156, 2018. PMID: 29543694. DOI: 10.1097/ MPG.0000000000001958

152 Emerick KM, Rand EB, Goldmuntz E, Krantz ID, Spinner NB and Piccoli DA: Features of Alagille syndrome in 92 patients: Frequency and relation to prognosis. Hepatology 29(3): 822829, 1999. PMID: 10051485. DOI: 10.1002/hep.510290331

153 Kamath BM, Yin W, Miller H, Anand R, Rand EB, Alonso E, Bucuvalas $\mathrm{J}$ and studies of pediatric liver transplantation: Outcomes of liver transplantation for patients with Alagille syndrome: The studies of pediatric liver transplantation experience. Liver Transpl 18(8): 940-948, 2012. PMID: 22454296. DOI: $10.1002 / 1$ t.23437

154 Lykavieris $\mathrm{P}$, Hadchouel $\mathrm{M}$, Chardot $\mathrm{C}$ and Bernard O: Outcome of liver disease in children with Alagille syndrome: A study of 163 patients. Gut 49(3): 431-435, 2001. PMID: 11511567. DOI: $10.1136 /$ gut.49.3.431

155 Lin HC, Le Hoang P, Hutchinson A, Chao G, Gerfen J, Loomes KM, Krantz I, Kamath BM and Spinner NB: Alagille syndrome in a Vietnamese cohort: Mutation analysis and assessment of facial features. Am J Med Genet A 158A(5): 1005-1013, 2012. PMID: 22488849. DOI: 10.1002/ajmg.a.35255

156 Berniczei-Royko A, Chałas R, Mitura I, Nagy K and Prussak E: Medical and dental management of Alagille syndrome: A review. Med Sci Monit 20: 476-480, 2014. PMID: 24658020. DOI: 10.12659/MSM.890577

157 Bonnet AL, Greset V and Davit-Beal T: Oral manifestations of Alagille syndrome. BMJ Case Rep 13(5): e234689, 2020. PMID: 32475824. DOI: 10.1136/bcr-2020-234689

158 Gilbert MA, Bauer RC, Rajagopalan R, Grochowski CM, Chao G, McEldrew D, Nassur JA, Rand EB, Krock BL, Kamath BM, Krantz ID, Piccoli DA, Loomes KM and Spinner NB: Alagille syndrome mutation update: Comprehensive overview of JAG1 and $\mathrm{NOTCH} 2$ mutation frequencies and insight into missense variant classification. Hum Mutat 40(12): 2197-2220, 2019. PMID: 31343788. DOI: 10.1002/humu.23879

159 Samejima H, Torii C, Kosaki R, Kurosawa K, Yoshihashi H, Muroya K, Okamoto N, Watanabe Y, Kosho T, Kubota M,
Matsuda O, Goto M, Izumi K, Takahashi T and Kosaki K: Screening for Alagille syndrome mutations in the JAG1 and $\mathrm{NOTCH} 2$ genes using denaturing high-performance liquid chromatography. Genet Test 11(3): 216-227, 2007. PMID: 17949281. DOI: $10.1089 /$ gte 2006.0519

160 Lin AE, Birch PH, Korf BR, Tenconi R, Niimura M, Poyhonen M, Armfield Uhas K, Sigorini M, Virdis R, Romano C, Bonioli E, Wolkenstein P, Pivnick EK, Lawrence M and Friedman JM: Cardiovascular malformations and other cardiovascular abnormalities in neurofibromatosis 1. Am J Med Genet 95(2): 108-117, 2000. PMID: 11078559. DOI: 10.1002/10968628(20001113)95:2<108::aid-ajmg4>3.0.co;2-0

161 Jutant EM, Jaïs X, Girerd B, Savale L, Ghigna MR, Perros F, Mignard X, Jevnikar M, Bourlier D, Prevot G, Tromeur C, Bauer F, Bergot E, Dauphin C, Favrolt N, Traclet J, Soumagne T, De Groote P, Chabanne C, Magro P, Bertoletti L, Gueffet JP, Chaouat A, Goupil F, Moceri P, Borie R, Fadel E, Wolkenstein P, Brillet PY, Simonneau G, Sitbon O, Humbert M and Montani D: Phenotype and outcomes of pulmonary hypertension associated with neurofibromatosis type 1. Am J Respir Crit Care Med 202(6): 843-852, 2020. PMID: 32437637. DOI: 10.1164/rccm.202001-0105OC

162 Rojnueangnit K, Xie J, Gomes A, Sharp A, Callens T, Chen Y, Liu Y, Cochran M, Abbott MA, Atkin J, Babovic-Vuksanovic D, Barnett CP, Crenshaw M, Bartholomew DW, Basel L, Bellus G, Ben-Shachar S, Bialer MG, Bick D, Blumberg B, Cortes F, David KL, Destree A, Duat-Rodriguez A, Earl D, Escobar L, Eswara M, Ezquieta B, Frayling IM, Frydman M, Gardner K, Gripp KW, Hernández-Chico $\mathrm{C}$, Heyrman $\mathrm{K}$, Ibrahim J, Janssens S, Keena BA, Llano-Rivas I, Leppig K, McDonald M, Misra VK, Mulbury J, Narayanan V, Orenstein N, GalvinParton P, Pedro H, Pivnick EK, Powell CM, Randolph L, Raskin S, Rosell J, Rubin K, Seashore M, Schaaf CP, Scheuerle A, Schultz M, Schorry E, Schnur R, Siqveland E, Tkachuk A, Tonsgard J, Upadhyaya M, Verma IC, Wallace S, Williams C, Zackai E, Zonana J, Lazaro C, Claes K, Korf B, Martin Y, Legius E and Messiaen L: High incidence of Noonan syndrome features including short stature and pulmonic stenosis in patients carrying NF1 missense mutations affecting p.Arg1809: Genotype-phenotype correlation. Hum Mutat 36(11): 10521063, 2015. PMID: 26178382. DOI: 10.1002/humu.22832

163 Cao H, Alrejaye N, Klein OD, Goodwin AF and Oberoi S: A review of craniofacial and dental findings of the RASopathies. Orthod Craniofac Res 20 Suppl 1: 32-38, 2017. PMID: 28643916. DOI: $10.1111 /$ ocr.12144

164 Pasmant E, Sabbagh A, Spurlock G, Laurendeau I, Grillo E, Hamel MJ, Martin L, Barbarot S, Leheup B, Rodriguez D, Lacombe D, Dollfus H, Pasquier L, Isidor B, Ferkal S, Soulier J, Sanson M, Dieux-Coeslier A, Bièche I, Parfait B, Vidaud M, Wolkenstein P, Upadhyaya M, Vidaud D and members of the NF France Network: NF1 microdeletions in neurofibromatosis type 1: from genotype to phenotype. Hum Mutat 31(6): E1506E1518, 2010. PMID: 20513137. DOI: 10.1002/humu.21271

165 Carroll WJ, Peck T, Jenkins TL and Karcioglu ZA: Periocular, periorbital, and orbital pathology in liver disease. Surv Ophthalmol 62(2): 134-149, 2017. PMID: 27863968. DOI: 10.1016/j.survophthal.2016.11.002

166 Humphreys R, Zheng W, Prince LS, Qu X, Brown C, Loomes $\mathrm{K}$, Huppert SS, Baldwin S and Goudy S: Cranial neural crest ablation of Jagged1 recapitulates the craniofacial phenotype of 
Alagille syndrome patients. Hum Mol Genet 21(6): 1374-1383, 2012. PMID: 22156581. DOI: $10.1093 / \mathrm{hmg} / \mathrm{ddr} 575$

167 Sant'Anna LB and Tosello DO: Fetal alcohol syndrome and developing craniofacial and dental structures - a review. Orthod Craniofac Res 9(4): 172-185, 2006. PMID: 17101024. DOI: 10.1111/j.1601-6343.2006.00377.x

168 Eberhart JK and Parnell SE: The genetics of fetal alcohol spectrum disorders. Alcohol Clin Exp Res 40(6): 1154-1165, 2016. PMID: 27122355. DOI: 10.1111/acer.13066

169 Olsen $\mathrm{J}$ and Tuntiseranee P: Is moderate alcohol intake in pregnancy associated with the craniofacial features related to the fetal alcohol syndrome? Scand J Soc Med 23(3): 156-161, 1995. PMID: 8602484. DOI: 10.1177/140349489502300304

170 Muggli E, Matthews H, Penington A, Claes P, O'Leary C, Forster D, Donath S, Anderson PJ, Lewis S, Nagle C, Craig JM, White SM, Elliott EJ and Halliday J: Association between prenatal alcohol exposure and craniofacial shape of children at 12 months of age. JAMA Pediatr 171(8): 771-780, 2017. PMID: 28586842. DOI: 10.1001/jamapediatrics.2017.0778

171 Blanck-Lubarsch M, Dirksen D, Feldmann R, Sauerland C and Hohoff A: 3D-analysis of mouth, nose and eye parameters in children with fetal alcohol syndrome (FAS). Int J Environ Res Public Health 16(14): 2535, 2019. PMID: 31315192. DOI: 10.3390/ijerph16142535

172 Gir AV, Aksharanugraha K and Harris EF: A cephalometric assessment of children with fetal alcohol syndrome. Am J Orthod Dentofacial Orthop 95(4): 319-326, 1989. PMID: 2705412. DOI: $10.1016 / 0889-5406(89) 90165-0$

173 Naidoo S, Norval G, Swanevelder S and Lombard C: Foetal alcohol syndrome: A dental and skeletal age analysis of patients and controls. Eur J Orthod 28(3): 247-253, 2006. PMID: 16644851. DOI: $10.1093 /$ ejo/cji109

174 Parviainen R, Auvinen J, Serlo W, Järvelin MR and Sinikumpu JJ: Maternal alcohol consumption during pregnancy associates with bone fractures in early childhood. A birth-cohort study of 6718 participants. Bone 137: 115462, 2020. PMID: 32485362. DOI: $10.1016 /$ j.bone.2020.115462

175 Hofer R and Burd L: Review of published studies of kidney, liver, and gastrointestinal birth defects in fetal alcohol spectrum disorders. Birth Defects Res A Clin Mol Teratol 85(3): 179-183, 2009. PMID: 19180632. DOI: 10.1002/bdra.20562
176 Whitaker SB and Bouquot JE: Estrogen and progesterone receptor status of central giant cell lesions of the jaws. Oral Surg Oral Med Oral Pathol 77(6): 641-644, 1994. PMID: 8065731. DOI: 10.1016/0030-4220(94)90327-1

177 Kamel A and Elsharkawy TM: Estrogen receptor proteins in peripheral and central giant cell granulomas of the jaws. Egypt Dent J 41(3): 1243-1246, 1995. PMID: 9497663.

178 Günhan M, Günhan O, Celasun B, Mutlu M and Bostanci H: Estrogen and progesterone receptors in the peripheral giant cell granulomas of the oral cavity. J Oral Sci 40(2): 57-60, 1998. PMID: 9680761. DOI: 10.2334 /josnusd .40 .57

179 Kehrer-Sawatzki H, Mautner VF and Cooper DN: Emerging genotype-phenotype relationships in patients with large NF1 deletions. Hum Genet 136(4): 349-376, 2017. PMID: 28213670. DOI: 10.1007/s00439-017-1766-y

180 Friedman JM and Birch PH: Type 1 neurofibromatosis: A descriptive analysis of the disorder in 1,728 patients. Am J Med Genet 70(2): 138-143, 1997. PMID: 9128932. DOI: 10.1002/ (sici)1096-8628(19970516)70:2<138::aid-ajmg7>3 .0.co;2-u

181 Venturin M, Guarnieri P, Natacci F, Stabile M, Tenconi R, Clementi M, Hernandez C, Thompson P, Upadhyaya M, Larizza $\mathrm{L}$ and Riva P: Mental retardation and cardiovascular malformations in NF1 microdeleted patients point to candidate genes in 17q11.2. J Med Genet 41(1): 35-41, 2004. PMID: 14729829. DOI: 10.1136/jmg.2003.014761

182 Kaplan I, Metzker A and Calderon S: Epidermal nevus syndrome with maxillary involvement. Int J Oral Maxillofac Surg 22(5): 298-300, 1993. PMID: 8245571. DOI: 10.1016/ s0901-5027(05)80520-x
Received February 27, 2021

Revised March 17, 2021

Accepted March 18, 2021 